\title{
The Chinese Warrants Bubble
}

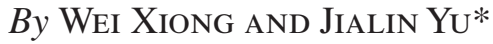

\begin{abstract}
In 2005-2008, over a dozen put warrants traded in China went so deep out of the money that they were almost certain to expire worthless. Nonetheless, each warrant was traded more than three times each day at substantially inflated prices. This bubble is unique in that the underlying stock prices make warrant fundamentals publicly observable and that warrants have predetermined finite maturities. This sample allows us to examine a set of bubble theories. In particular, our analysis highlights the joint effects of short-sales constraints and heterogeneous beliefs in driving bubbles and confirms several key findings of the experimental bubble literature. (JEL G12, G13, O16, P34)
\end{abstract}

Asset price bubbles, that is, asset prices that exceed the assets' fundamental value, have always been a subject of interest to economists. Clear identification of a price bubble is challenging, however, due to the difficulty in measuring an asset's fundamental value. There is an open debate about whether each historical episode constitutes a bubble. For example, Peter Garber (2000) proposes market fundamental explanations for three famous bubbles, the Dutch tulip mania (1634-37), the Mississippi bubble (1719-20) and the closely connected South Sea bubble (1720). Lubos Pastor and Pietro Veronesi (2006) challenge the existence of an Internet bubble in the late 1990s. The difficulty in measuring asset fundamentals complicates the analysis of economic mechanisms that drive up price bubbles, which in turn makes predicting future bubbles even more challenging. Instead, academic literature heavily relies on laboratory settings.

In this article, we use a unique data sample from China's warrants market to study asset price bubbles. In 2005-2008, 18 Chinese companies issued put warrants with long maturities ranging from six months to two years. These warrants give their holders the right to sell the issuing companies' stocks at predetermined strike prices during a prespecified exercise period. The dramatic boom in the Chinese stock market between 2005 and 2007 pushed most of these put warrants so deep out of the money that they were almost certain to expire worthless. However, they had become targets of frenzied speculation, which generated a spectacular bubble as dramatic as, if not more

\footnotetext{
* Xiong: Department of Economics and Bendheim Center for Finance, Princeton University, 26 Prospect Avenue, Princeton, NJ 08540 (e-mail: wxiong@ princeton.edu); Yu: Graduate School of Business, Columbia University, 421 Uris Hall, 3022 Broadway, New York, NY 10027 (e-mail: jy2167@ columbia.edu). We thank Markus Brunnermeier, Zhiwu Chen, Simon Gervais, Lin Peng, Jose Scheinkman, Kathy Yuan, and seminar and conference participants at Central University of Finance and Economics, Columbia Business School, Princeton University, Renmin University of China, Shenzhen Stock Exchange, Singapore Management University, Yale University, University of Hong Kong, 2008 CKGSB Summer Finance Conference at Hangzhou, 2009 NBER Behavioral Finance Conference, and the second Paul Woolley Conference on Capital Market Dysfunctionality at London School of Economics. We are especially grateful to three anonymous referees for extensive and constructive comments.

$\dagger$ To view additional materials, visit the article page at http://www.aeaweb.org/articles.php?doi=10.1257/aer.101.6.2723.
} 
so than, any other bubble episode. For each warrant, billions of yuan was traded with an average daily turnover rate over 300 percent, and at substantially inflated prices. Several features make these warrants particularly appealing for analyzing bubbles: First, we can reliably measure the warrants' fundamental values to be close to zero by using the underlying stock prices; second, the publicly observable stock prices also make the warrant fundamentals observable to all market participants; and third, these warrants have predetermined finite maturities. These features so far are available only in laboratory environments. This sample thus allows us to examine a set of bubble theories and to confirm several key findings of the experimental studies.

We analyze the market dynamics of the 18 put warrants. We use a number of measures to quantify these warrants' fundamental values. One of these measures is based on the widely used Black-Scholes model. Each warrant, with the exception of only one, had a zero-fundamental period in which its Black-Scholes value dropped to economically negligible levels, which is defined to be below half of the minimum trading tick of 0.1 penny (one penny is one hundredth of one yuan). While one might argue that the Black-Scholes model may not be accurate in measuring fundamental values of these warrants, a Black-Scholes value of less than 0.05 penny is a reliable indication that the warrant only has a tiny probability, if any, of being in the money at expiration date. The length of the zero-fundamental period ranged from three trading days to 165 trading days, with an average of 48 trading days per warrant. Despite its negligible fundamental value in this period, each warrant had been traded at substantially higher prices with an average of 0.948 yuan. In addition, prices varied considerably across warrants.

We also construct less model-specific upper bounds for the warrants' fundamental values. One of the bounds is based on the restriction in China that stock price is not allowed to drop more than 10 percent each day. Thus, current stock price implies an upper bound on warrant payoff at expiration. Another even more relaxed upper bound is the put warrant's strike price, which can be realized only if the stock price drops to zero before warrant expiration. Both bounds had been violated in the sample. Taken together, there is little doubt about the existence of a bubble because the warrant prices exceeded not only the fundamental values implied by the BlackScholes model, but also the model-free upper bounds.

Like many historical bubble episodes, the warrants bubble was accompanied by a trading frenzy and by extraordinary price volatility. Each warrant in its zero-fundamental period had an average daily turnover rate of 328 percent, an average daily volume of 1.29 billion yuan, and an average return volatility of 271 percent per annum. On an extreme day, the ZhaoHang put warrant had a volume of 45.68 billion yuan (roughly 7 billion US dollars) even though the warrant was virtually worthless from exercising. On their last trading days, these warrants had an average turnover rate of 1,175 percent in four hours of trading time, which means about 100 percent turnover every 20 minutes!

What drove investors to trade so much and pay such inflated prices? These warrants had only a small and insignificant return correlation with the underlying stocks in their zero-fundamental periods. Thus, it is difficult to argue that investors traded these warrants to hedge daily fluctuations of the underlying stocks. One might argue that put warrants allow their holders to hedge more severe jump-to-ruin risk of the stocks. Interestingly, since each warrant's exercise period expires five business days 
after its last trading day, its last trading price provides an estimate of premium for hedging such jump-to-ruin risk in the remaining exercise period. The jump premium averages 0.9 penny per day, which can explain only a small fraction of the warrant prices during the trading days if the same representative investor had determined the warrant prices on the last and earlier trading days.

The finite maturity of the warrants also prevents a rational bubble suggested by Olivier Blanchard and Mark Watson (1983), who show that a rational bubble can exist for an asset with an infinite life as long as the bubble is expected to grow at a rate equal to the discount rate. The limited presence of institutional investors in the warrants market makes it unlikely that the inflated warrant prices were driven by institutional investors' agency problems, e.g., Franklin Allen and Gary Gorton (1993) and Allen and Douglas Gale (2000). There is also little evidence of positive skewness in the warrant returns to support the hypothesis that investors treated these warrants as lottery tickets, e.g., Nicholas Barberis and Ming Huang (2008).

The restrictive legal ban on short-selling financial securities (including warrants) in China and investors' heterogeneous beliefs about warrant fundamentals make the resale option theory building on the joint effects of heterogeneous beliefs and shortsales constraints, e.g., Michael Harrison and David Kreps (1978), Stephen Morris (1996), Jose Scheinkman and Xiong (2003), and Harrison Hong, Scheinkman, and Xiong (2006), particularly relevant for explaining the warrants bubble. Although investors can observe the current stock prices, valuing the deep-out-of-the-money put warrants requires a nontrivial assessment of the stocks' future tail distribution. It is reasonable for different investors to hold heterogeneous beliefs about such distribution. Anticipating other investors' beliefs to fluctuate over time, a warrant buyer may be willing to pay an inflated price because he has the option to resell the warrant to someone else in the future for a speculative profit.

The warrants bubble sample confirms several key implications of the resale option theory. Scheinkman and Xiong (2003) predict that the size of a price bubble is positively related to trading volume and return volatility. The more investors disagree about future price movement, the more intensively they trade with each other, and, at the same time, the more they are willing to pay for the resale option. When asset return is more volatile, investors also tend to disagree more, which in turn makes the bubble larger. Hong, Scheinkman, and Xiong (2006) derive that the size of bubble is negatively related to asset float (i.e., number of tradable shares) and time remaining for trading. When investors have a limited risk-bearing capacity and when there is a larger asset float, investors expect that it takes a more optimistic belief of the future buyer to make a profit, thus leading to a smaller bubble. When less trading time remains, there are fewer resale opportunities and therefore a smaller price bubble. Our panel regression analysis provides evidence supporting these theory predictions.

Identifying bubbles in real time is challenging. Market participants and regulators may not have the luxury of precisely measuring asset fundamentals as we have in analyzing the warrants bubble. However, the bubble properties we identify, and, in particular, that bubbles tend to be accompanied by trading frenzy and large price volatility, can help sharpen real-time bubble detection in other more complex asset markets.

Our study confirms a key finding of the experimental studies that bubbles can arise even when asset maturities are finite and asset fundamentals are publicly observable. This phenomenon was initially discovered by Vernon L. Smith, Gerry L. Suchanek, 
and Arlington W. Williams (1988) and later replicated by many other studies, e.g., David Porter and Smith (1995); Vivian Lei, Charles Noussair, and Charles Plott (2001); Martin Dufwenberg, Tobias Lindqvist, and Evan Moore (2005); Lucy Ackert et al. (2006); Ernan Haruvy and Noussair (2006); Haruvy, Yaron Lahav, and Noussair (2007); Shinichi Hirota and Shyam Sunder (2007); and Reshmaan Hussam, Porter, and Smith (2008), under various treatments. Our study also corroborates these studies in highlighting short-sales constraints as a key driver of asset bubbles.

Smith, Suchanek, and Williams (1988) argue that noncommon knowledge of rationality is the key to bubbles discovered in the experimental studies. When traders doubt about the rationality of other traders, they will speculate that future prices may not track asset fundamentals and would instead provide opportunities for trading gains. As the warrants bubble sample spans three years, it allows us to examine whether learning by investors through trading can help alleviate the bubble. Interestingly, we find no evidence of investor learning in alleviating the bubble. This result suggests that either noncommon knowledge of rationality is inconsequential or inflow of new investors is important for understanding prolonged price bubbles.

In analyzing the time-series dynamics of the warrants bubble, we also find evidence of positive feedback to past warrant returns in both warrant returns and turnover changes at short time intervals of several minutes, consistent with the feedback loop theory of bubbles advocated by Robert Shiller (2000). Furthermore, we find asymmetric profits from momentum strategies of buying winners and selling losers-shorting losers can generate positive and statistically significant profits, but buying winners cannot. On one hand, this asymmetry confirms the importance of short-sales constraints in preventing smart investors from taking advantage of the persistent negative warrant returns. On the other hand, it also indirectly implies the presence of smart investors in actively riding the bubble, e.g., Dilip Abreu and Markus Brunnermeier (2003) and Brunnermeier and Stefan Nagel (2004). By doing so, they might have eliminated additional opportunities for such momentum trades.

The paper is organized as follows. Section I provides an introduction of China's warrant market. Section II describes the price bubble. We examine the driving mechanisms of the bubble in Section III and conclude in Section IV.

\section{China's Warrants Market}

Despite China's rapid economic growth over the past 30 years, its financial markets are still in development and offer far fewer investment choices than the markets in other more developed economies. The central government had been very cautious about new financial products because of the concern that they might be misused or abused by Chinese investors. In fact, it had closed out all financial derivatives markets since 1995 after a notorious manipulation scandal by a security firm in the government bond futures market. The government's share reform in 2005 provided an opportunity for the China Securities Regulatory Commission (CSRC) to reintroduce financial derivatives to the market, without being rejected by the central government. Before the reform, most shares (about two thirds) of public firms were owned either directly by the government or indirectly through its local agencies. These shares were restricted from trading in the public market. Realizing that bureaucrats and government agents are not suitable for the responsibility of enforcing governance 
of public firms, in 2005 the central government announced a plan to convert its large non-tradable share holdings into tradable shares and eventually float them in the market. However, this plan encountered resistance from investors who worried that a dramatic increase in the number of freely tradable shares would depress share prices and cause large losses in their holdings. To persuade the public to accept the share reform plan, the government decided to compensate holders of floating shares for their potential losses. Seizing this opportunity, the CSRC allowed some firms involved in the share reform to issue warrants as part of their compensation packages to public investors.

Warrants are essentially financial options issued by publicly listed firms. There are two basic types. A call warrant gives its holder the right to buy stock from the issuing firm at a predetermined strike price during a prespecified exercise period, while a put warrant gives its holder the right to sell stock back to the issuing firm. Both call and put warrants derive their values from the underlying stock price: the value of a call warrant increases with the stock price, while that of a put warrant decreases.

To maintain the usual advantages of financial derivatives for hedging and speculation purposes, the CSRC has provided a more trading-friendly environment for the warrants market than for the stock market, which is reflected in several dimensions. First, stock trading is subject to the so-called " $\mathrm{T}+1$ " rule, which requires investors to hold their stocks for at least one day before selling. Warrants trading is subject to the "T +0 " rule, which allows investors to sell warrants they purchase earlier-on the same day. As a result, investors can pursue day-trading strategies in warrants but not in stocks.

Second, investors incur a lower transaction cost when trading warrants. When trading stocks (either buying or selling), investors pay a stamp tax to the government, a registration fee to the stock exchange, and a brokerage fee. The stamp tax is a flat percentage of the total proceeds. The tax rate has changed several times in the past, ranging from 0.1 to 0.3 percent. The registration fee is 0.1 percent of the total proceeds. The trading commission is negotiable with brokers and is capped at 0.3 percent of the total proceeds. Investors are exempted from paying any stamp tax and registration fee when trading warrants. They still pay a brokerage fee, which is also negotiable and is capped at 0.3 percent of the total proceeds. Because of the large volume in the warrants market, brokers usually charge a lower trading commission on warrants than on stocks.

Third, warrants have a wider daily price change limit. The CSRC imposes a 10 percent limit on daily price increase or decrease of any stock traded on the two stock exchanges in Shanghai and Shenzhen. Once the price of a stock rises or falls by 10 percent relative to the previous day's closing price, the trading of this stock is halted for the day. The daily permissible price increase (decrease) of a warrant in yuan is equal to the daily permissible price increase (decrease) of the underlying stock in yuan, multiplied by 1.25 and the warrant's exercise ratio. Since a warrant

\footnotetext{
${ }^{1}$ For example, consider the NanHang put warrant on November 2, 2007. On the previous trading day, the warrant's closing price was 1.122 yuan, and the underlying NanHang stock's closing price was 21.61 yuan. The warrant had an exercise ratio of 0.5 , i.e., one share of the warrant gave its holder the right to sell 0.5 share of NanHang stock to the issuing firm. With the 10 percent daily price change limit, the price of NanHang stock was allowed to increase or decrease by 2.16 yuan on this day. Then, the warrant price was allowed to increase or decrease by $2.16 \times 1.25 \times 0.5=1.35$ yuan, which corresponded to 120 percent of the warrant's closing price from the previous day.
} 
has a high leverage ratio, its price-change limit is much wider in percentage terms than the limit on the underlying stocks. In practice, warrants seldom hit their daily price-change limit despite their dramatic price volatility, which we will discuss in the next section.

Despite the goodwill of the CSRC in providing a friendly environment for investors to use warrants as a tool to hedge or speculate on the underlying stocks, the warrants market attracted a speculative frenzy of its own, as we will describe in the next section.

Finally, it is important to note that investors are prohibited by law from short-sell-

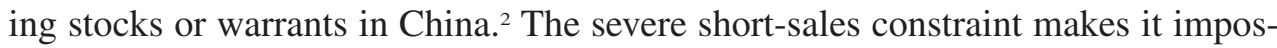
sible for investors to arbitrage any stock or warrant's overvaluation relative to its fundamental. Meanwhile, companies cannot easily arbitrage overvaluation of their warrants by issuing more warrants because new issuance is subject to restrictive quota constraints set by the central government.

The Shanghai Stock Exchange (SHSE), one of the two main stock exchanges, had experimented with a limited shorting mechanism for the SHSE-traded warrants by allowing a group of designated brokerage firms to create additional shares of the SHSE-traded warrants. When a designated firm wants to create more shares of a warrant, it must obtain approval from the SHSE, which weighs a set of unwritten factors in making the decision. 3 The created warrants are traded in the market undistinguished from the original warrants, and the firm can buy back warrants from the market to offset its earlier creation. ${ }^{-1}$ The creation mechanism caused the floating shares of the SHSE warrants to change over time, but it did not eliminate the overvaluation of these warrants because of the program's limited scope.

\section{The Price Bubble in Put Warrants}

In total, 18 put warrants and 37 call warrants had been issued for public trading. Among them, 39 were traded on the SHSE and 16 on the Shenzhen Stock Exchange (SZSE). Our analysis focuses on the 18 put warrants because most of them went deep out of the money during the stock market boom in 2005-2007. This makes it easier for us to identify their fundamental values based on the underlying stock prices. In contrast, some of the call warrants expired in the money, while the others were out of the money. As such, determining the fundamental values of the call warrants is more challenging and crucially depends on specific pricing models of call warrants.

\footnotetext{
${ }^{2}$ The CSRC started to allow shorting of a selected set of stocks only in 2010 , which does not affect our analysis of the warrant sample from 2005 to 2008 .

${ }^{3}$ The SHSE could not allow the brokerage firms to issue stock-settled put warrants at a quantity substantially more than the floating shares of the firm stocks, because otherwise the warrant holders wouldn't be able to exercise their in-the-money put warrants at expiration. The SHSE had also faced enormous public pressure and criticism after these warrants expired out of the money, which caused many individual investors to lose money while the brokerage firms made large profits from issuing the warrants.

${ }^{4}$ Creations and cancellations are publicly disclosed by the SHSE within the same day.

${ }^{5}$ The CSRC had stopped firms from issuing more put warrants after 2007, in part because of the speculative frenzy in the put warrants.

${ }^{6}$ Five firms had simultaneously issued both put and call warrants, but with different strike prices. This difference makes it difficult to analyze potential violation of put-call parity.
} 
We purchase data on all of the 18 put warrants from the GTA data company. ${ }^{\text {Q }}$ Our data include the initial contract terms, later contract modifications (such as adjustments for stock splits), daily price information (open, close, high, and low), daily trading volume, intraday transactions (time, price, and quantity), and warrant exercises. To ensure the quality and accuracy of the data, we have also cross-checked the data with the exchanges. We also substitute the information about the underlying stocks from the China Stock Market and Accounting Research (CSMAR) database provided by the Wharton Research Data Services (WRDS).

\section{A. The WuLiang Put Warrant}

The WuLiang put warrant provides a vivid example of the bubble in the Chinese warrants market. On April 3, 2006, WuLiangYe Corporation, a liquor producer in China, issued 313 million shares of put warrants on the SZSE. The warrant has a maturity of two years with expiration date of April 2, 2008. Investors are allowed to freely trade the warrant before March 26, 2008. After the last trading day, warrant holders have five business days between March 27, 2008 and April 2, 2008 to exercise the warrant. The put warrant was issued in the money with an initial stock price of 7.11 yuan per share and a strike price of 7.96 yuan per share. At issuance, each share of the warrant gives its holder the right to sell one share of WuLiang stock to WuLiang Ye Corporation during the exercise period.

Figure 1 plots the daily closing prices of WuLiang stock and the put warrant during its lifetime. The WuLiang stock had a stock split of 1 to 1.402 during the life of the warrant. As the warrant is adjusted for the stock split and dividend payouts, Figure 1 is based on the presplit share unit but adjusts for dividend payout. For consistency, we use presplit share units throughout our discussion of the WuLiang warrant in this section. The WuLiang stock price increased from 7.11 yuan on April 3, 2006 to a peak of 71.56 yuan on October 15, 2007, and then retreated to around 26 yuan when the warrant expired. While the put warrant was initially issued in the money, the big runup of WuLiang stock price soon pushed the warrant out of money after two weeks, and it never came back in the money. Despite this, the warrant price moved up with the stock price from an initial price of 0.99 yuan to as high as 8.15 yuan in June 2007 and only gradually fell back to one penny at the last minute of the last trading day.

Was there a bubble in the WuLiang put warrant price? The warrant's fundamental value is determined by the price and return volatility of the WuLiang stock. The widely used Black-Scholes model provides a convenient tool to estimate the warrant's fundamental value. ${ }^{\mathbb{8}}$ We use WuLiang stock's daily closing price and previous one-year rolling daily return volatility to compute the warrant's Black-Scholes value. ${ }^{0}$ Figure 1 plots the Black-Scholes value together with the market price. The

\footnotetext{
${ }^{7}$ The same company supplies the Chinese stock market data to the WRDS database, which is commonly used in the finance academic community.

${ }^{8}$ Exercises of warrants can lead to a dilution effect on the underlying stock prices, which in turn feeds back to the warrant values. This dilution effect is significant only when warrants are either in or close to the money. As our analysis focuses on the sample in which the put warrants were deep out of money, we ignore the dilution effect.

${ }^{9}$ We have implemented a binomial model to adjust for the extended five-day exercise period after the end of WuLiang warrant trading in computing the Black-Scholes value.
} 


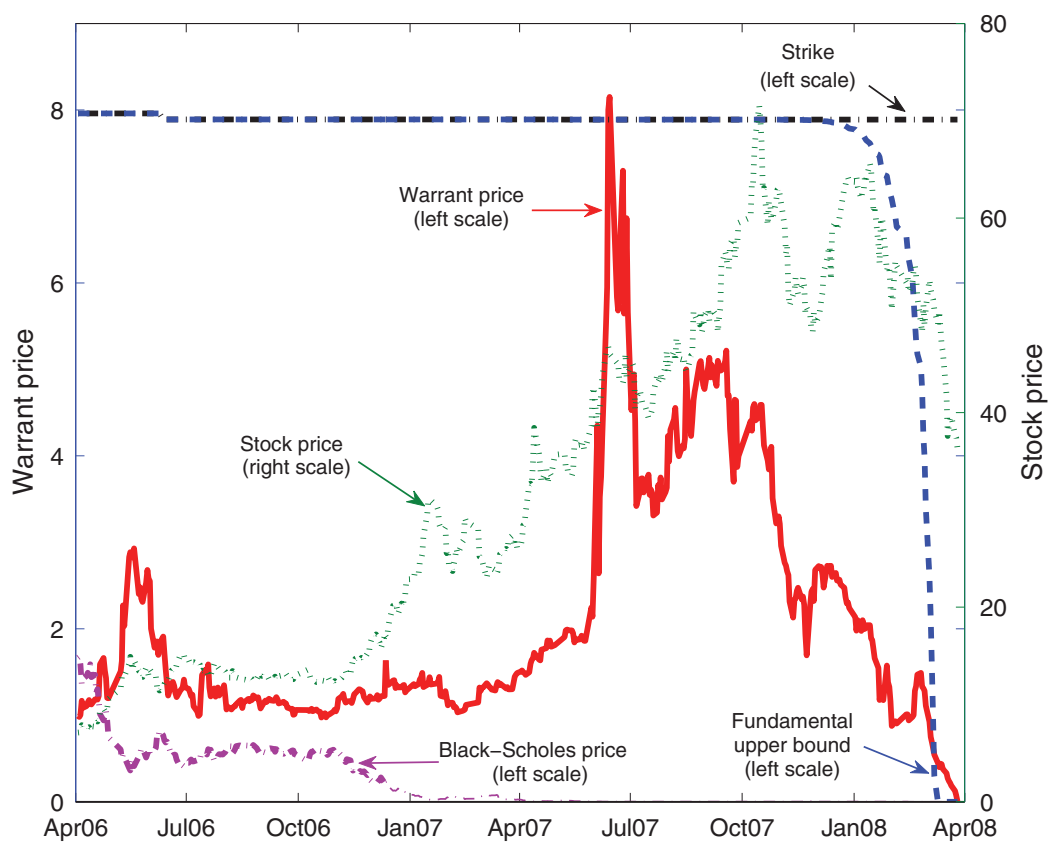

Figure 1. Prices of WuLiang Put Warrant

Notes: This figure shows the daily closing prices of WuLiang stock and its put warrant, along with WuLiang warrant strike price, upper bound of its fundamental value assuming WuLiang stock price drops 10 percent every day before expiration (maximum allowed per day in China's stock market), and its Black-Scholes price using WuLiang stock's previous one-year rolling daily return volatility.

warrant was traded at prices above the Black-Scholes value throughout its life, except for a brief two-week period in the beginning. For convenience, we say that the Black-Scholes value is zero if it falls below an economically negligible level, marked at 0.05 penny (half of the minimum trading tick of 0.1 penny). The warrant's Black-Scholes value dropped to zero after July 23, 2007 and stayed at zero for its remaining nine-month lifetime. Notably, during this zero-fundamental period, the warrant mostly traded for several yuan! The price dropped to below one yuan only in the last few trading days.

There are two caveats for using the Black-Scholes model to measure the warrant's fundamental value. First, the Black-Scholes model builds on an arbitrage mechanism linking the price of a warrant to that of its underlying stock. Investors cannot arbitrage any price discrepancy between the two in China because they cannot short sell either the stock or the warrant. Second, the Black-Scholes model relies on a set of assumptions about the underlying stock price dynamics, such as its being a geometric Brownian motion process with constant volatility, which may not fit the stock price dynamics in China. These considerations caution us not to overinterpret the exact Black-Scholes value. 10 Nevertheless, when the Black-Scholes value of a

\footnotetext{
${ }^{10}$ Because of the short-sales constraints on the underlying stock, the stock might be overvalued by its optimists and therefore be exposed to jump-to-ruin risk. The put warrant allows its holder to hedge such risk. As the BlackScholes model does not account for jump risk, it tends to undervalue the warrant. We will explicitly estimate the premium for the jump-to-ruin risk in Section IIIA.
} 
warrant drops below 0.05 penny, it indicates that there is only a tiny probability, if any, that the warrant could be in the money at expiration and that the warrant has virtually no value from exercising. Moreover, while the valuation error of the BlackScholes model might be large in percentage terms, it is likely small in absolute terms (Shmuel Hauser and Beni Lauterbach 1997).

We also construct a model-free upper bound to demonstrate overvaluation of the warrant, based on the following consideration. The WuLiang stock price, like other common stocks traded in China, is not allowed to drop by more than 10 percent each day. This implies that the stock price on an earlier day puts a floor on the stock price before the warrant's expiration day. Consequently, the warrant payoff is capped by the implied floor on the stock price. To illustrate this cap, consider March 7, 2008, 13 trading days before the warrant's last trading day and 18 days before its expiration day. WuLiang stock closed at 50.61 yuan on this day. This price implies that the lowest level WuLiang stock price could reach before the warrant expiration is $50.61 \times(1-0.1)^{18}=7.596$ yuan, assuming that the stock would hit its daily price drop limit in 18 consecutive days. Then, the maximum payoff from the put warrant could only be 0.294 , which is the difference between the warrant's strike price, 7.89 yuan, and the lowest possible stock price before expiration, 7.596 yuan. The closing price of the warrant on this day stood at 0.543 yuan, which was higher than the warrant's fundamental upper bound.

Figure 1 also plots the fundamental upper bound based on WuLiang stock's closing price on each day. This upper bound dropped to zero and stayed there right after March 7, 2008. Thus, the price of the WuLiang put warrant was above its maximum payoff implied by the underlying stock price and the daily price drop limit for 14 consecutive trading days before expiration!

The strike price provides an even more relaxed upper bound on the warrant payoff. A put warrant can generate a payoff equal to its strike price only when the stock price drops to zero before its expiration. Figure 1 shows that the price of the WuLiang put warrant was even above its strike price of 7.89 yuan on June 13 and 14, 2007. On June 13 , the warrant reached an intraday high of 8.51 yuan and closed at 8.00 yuan. On June 14 , it reached an intraday high of 9.33 yuan and closed at 8.15 yuan.

To sum up, there is clear evidence that there was a price bubble in the WuLiang put warrant. Its price exceeded several reasonable estimates of its fundamental value-it exceeded the Black-Scholes value by large margins; it went above the fundamental upper bound implied by the current stock price and the daily stock price drop limit; and it even exceeded the strike price.

Like the Internet bubble analyzed by Owen Lamont and Richard Thaler (2003) and Eli Ofek and Matthew Richardson (2003) and many other historical bubble episodes, the price bubble in the WuLiang put warrant came with a trading frenzy and extraordinary volatility. Figure 2 plots its daily turnover rate and daily volume (measured in billions of yuan). The daily turnover rate was impressive. It averaged 140 percent and shot up to as high as 1,841 percent on the last trading day, i.e., the warrant changed hands more than 18 times on that day. The warrant had an average daily volume of 1.06 billion yuan (roughly 150 million US dollars because the exchange rate was about 7 yuan/dollar during this period). The volume was especially high during the second half of the warrant's life after July 23, 2007 when the warrant's Black-Scholes value dropped to zero. The volume rose to as high as 12 

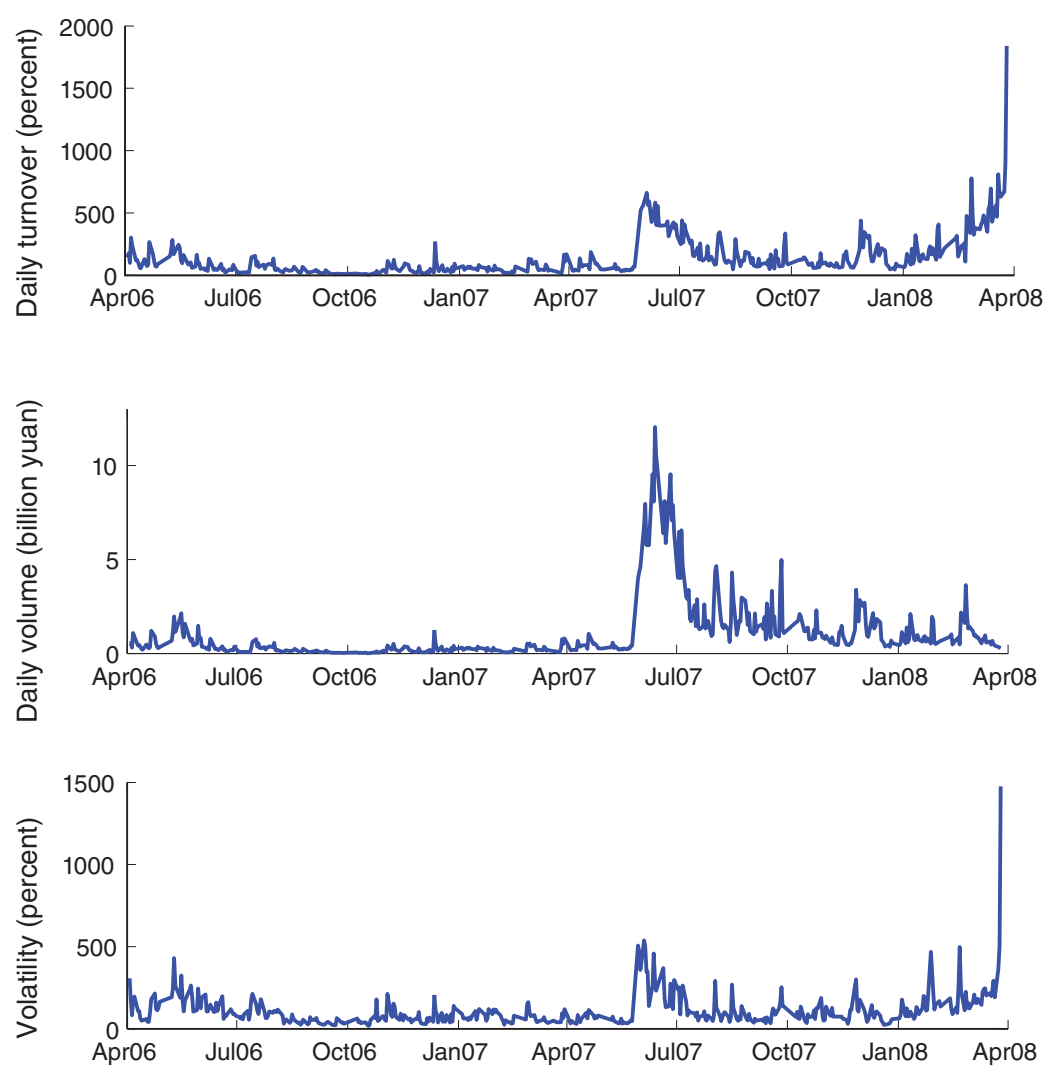

Figure 2. Volume and Volatility of Wuliang Put Warrant

Note: This figure shows the WuLiang put warrant's daily turnover, daily trading volume (in billion yuan), and 5-minute return volatility (annualized) in each trading day.

billion yuan on a single day in July 2007. In other words, investors traded a pile of essentially worthless paper (from exercising) for almost 2 billion US dollars on a single day! If we assume a 0.2 percent trading commission for both buyers and sellers to pay their brokerage firms, this warrant generated a trading commission on the order of 8 million US dollars on that day.

To put the trading frenzy in the WuLiang put warrant in perspective, it is useful to compare its turnover rate with that in a few other markets. Stocks listed on New York Stock Exchange, a liquid market by many measures, have a turnover rate of about 100 percent per year. The WuLiang put warrant's turnover rate on average is 340 times higher than that of NYSE stocks and on the last trading day is 4,600 times higher. Another useful benchmark is Palm stock, one of the iconic stocks in the Internet bubble. As documented by Lamont and Thaler (2003), Palm stock in its glorious days of early 2000 was traded at a rate of 100 percent per week. The WuLiang put warrant's turnover rate on average is 7 times the Palm's turnover rate and on the last trading day is 90 times higher. The WuLiang put warrant is extremely active even by the Chinese standard. A-share stocks (shares issued to domestic residents) on the Shanghai and Shenzhen stock exchanges have an average turnover rate of 500 percent per year, e.g., Jianping Mei, Scheinkman, and Xiong (2009), while 
TABLE 1 -SUMmary INFORMATION OF THE 18 PUt WARRANTS

\begin{tabular}{|c|c|c|c|c|c|c|c|c|}
\hline \multirow[b]{2}{*}{$\begin{array}{l}\text { Name } \\
\text { (exchange) }\end{array}$} & \multirow{2}{*}{$\begin{array}{c}\text { Warrant } \\
\text { shares } \\
\text { (million) }\end{array}$} & \multicolumn{2}{|c|}{ Trading period } & \multicolumn{3}{|c|}{ Price at trading end } & \multicolumn{2}{|c|}{ Exercise period } \\
\hline & & Begin & End & $\begin{array}{l}\text { Stock } \\
\text { price }\end{array}$ & $\begin{array}{l}\text { Strike } \\
\text { price }\end{array}$ & $\begin{array}{l}\text { Exercise } \\
\text { ratio }\end{array}$ & Begin & End \\
\hline WanKe (SZ) & 2,140 & $12 / 5 / 2005$ & $8 / 28 / 2006$ & 6.79 & 3.638 & 1 & $8 / 29 / 2006$ & $9 / 4 / 2006$ \\
\hline ShenNeng (SZ) & 438 & $4 / 27 / 2006$ & $10 / 19 / 2006$ & 7.25 & 6.692 & 1 & $10 / 20 / 2006$ & $10 / 26 / 2006$ \\
\hline WuGang (SH) & 474 & $11 / 23 / 2005$ & $11 / 15 / 2006$ & 3.35 & 2.83 & 1 & $11 / 16 / 2006$ & $11 / 22 / 2006$ \\
\hline JiChang (SH) & 240 & $12 / 23 / 2005$ & $12 / 15 / 2006$ & 7.94 & 6.9 & 1 & $3 / 23 / 2006$ & $12 / 22 / 2006$ \\
\hline YuanShui (SH) & 280 & $4 / 19 / 2006$ & $2 / 5 / 2007$ & 6.54 & 4.9 & 1 & $2 / 6 / 2007$ & $2 / 12 / 2007$ \\
\hline HuChang ( $\mathrm{SH})$ & 568 & $3 / 7 / 2006$ & $2 / 27 / 2007$ & 25.52 & 13.36 & 1 & $3 / 6 / 2007$ & $3 / 6 / 2007$ \\
\hline BaoGang (SH) & 715 & $3 / 31 / 2006$ & $3 / 23 / 2007$ & 5.7 & 2.37 & 1 & $3 / 26 / 2007$ & $3 / 30 / 2007$ \\
\hline WanHua (SH) & 85 & $4 / 27 / 2006$ & $4 / 19 / 2007$ & 38.75 & 9.22 & 1.41 & $4 / 20 / 2007$ & $4 / 26 / 2007$ \\
\hline GangFan (SZ) & 233 & $12 / 5 / 2005$ & $4 / 24 / 2007$ & 10.72 & 3.16 & 1.535 & $5 / 8 / 2007$ & $5 / 8 / 2007$ \\
\hline $\operatorname{HaiEr}(\mathrm{SH})$ & 607 & $5 / 22 / 2006$ & $5 / 9 / 2007$ & 15.79 & 4.29 & 1 & $5 / 10 / 2007$ & $5 / 16 / 2007$ \\
\hline YaGe (SH) & 635 & $5 / 22 / 2006$ & $5 / 14 / 2007$ & 26.44 & 4.09 & 1 & $5 / 17 / 2007$ & $5 / 21 / 2007$ \\
\hline MaoTai (SH) & 432 & $5 / 30 / 2006$ & $5 / 22 / 2007$ & 94.84 & 30.3 & 0.25 & $5 / 29 / 2007$ & $5 / 29 / 2007$ \\
\hline JiaFei (SZ) & 120 & $6 / 30 / 2006$ & $6 / 22 / 2007$ & 45.21 & 15.1 & 1 & $6 / 25 / 2007$ & $6 / 29 / 2007$ \\
\hline ZhaoHang (SH) & 2,241 & $3 / 2 / 2006$ & $8 / 24 / 2007$ & 39.04 & 5.45 & 1 & $8 / 27 / 2007$ & $8 / 31 / 2007$ \\
\hline ZhongJi (SZ) & 424 & $5 / 25 / 2006$ & $11 / 16 / 2007$ & 24.11 & 7.302 & 1.37 & $11 / 19 / 2007$ & $11 / 23 / 2007$ \\
\hline HuaLing (SZ) & 633 & $3 / 2 / 2006$ & $2 / 22 / 2008$ & 12.45 & 4.718 & 1 & $2 / 27 / 2008$ & $2 / 29 / 2008$ \\
\hline WuLiang (SZ) & 313 & $4 / 3 / 2006$ & $3 / 26 / 2008$ & 25.92 & 5.627 & 1.402 & $3 / 27 / 2008$ & $4 / 2 / 2008$ \\
\hline NanHang (SH) & 1,400 & $6 / 21 / 2007$ & $6 / 13 / 2008$ & 8.48 & 7.43 & 0.5 & $6 / 20 / 2008$ & $6 / 20 / 2008$ \\
\hline
\end{tabular}

Notes: This table shows, for each put warrant, its name, exchange (SZ for Shenzhen, SH for Shanghai), total shares outstanding at the start of warrant trading, trading period, the closing prices of the underlying stock and the warrant on the last trading day, the exercise ratio (number of underlying stocks per warrant) on the last trading day, and the exercise period. The warrants are sorted according to the expiration date of their exercise periods.

across the Taiwan strait on the Taiwan Stock Exchange stocks have an average turnover rate of 300 percent per year, e.g., Brad Barber et al. (2009).

Figure 2 also plots the daily return volatility of the WuLiang put warrant constructed from its intraday five-minute returns. 11 The annualized warrant volatility varied dramatically over time between 18 percent and 1,475 percent. The average was 111 percent. It is also interesting to note that while there was a large return volatility, the price of the WuLiang warrant had not crashed down to zero before its last day of trading.

\section{B. Other Warrants}

Table 1 provides a complete list of the 18 publicly traded put warrants, in the order of their expiration dates. These warrants have a long maturity, ranging from six months to two years, and an exercise period right before the expiration date. The exercise period lasts for five business days, with the exception of the JiChang put warrant which has an exercise period of nine months. These warrants are adjusted for any stock split and dividend payout during their lifetime.

The China Securities Index CSI 300, a representative price index for China's stock market, shot up from 818 points in June 2005 to an all-time peak of 5,877 points in October 2007. This market runup had caused all of the 18 put warrants to

\footnotetext{
${ }^{11}$ To mitigate the effect of microstructure noise on volatility estimation (see, for example, Yacine Aitt-Sahalia, Per Mykland, and Lan Zhang 2005), we feature five-minute return volatility as opposed to transaction-to-transaction return volatility, though the result is similar using alternative measures of volatility. The Chinese warrant market is very liquid using a number of traditional measures of liquidity. Therefore, using five-minute return to measure volatility likely strikes a balance between sample size and microstructure noise.
} 
expire out of the money. Among them, 14 were 20 percent out of the money (i.e., the stock prices were 20 percent higher than the strike prices) and 13 were 50 percent out of the money.

Each of the put warrants had experienced a price bubble similar to that exhibited by the WuLiang put warrant. Table 2 shows that 17 of the 18 put warrants had zero-fundamental periods in which their Black-Scholes values dropped below 0.0005 yuan. $\frac{12,13}{.2}$ Yet their market prices were substantially higher than zero with an average of 0.948 yuan, which was only slightly lower than the average warrant price in the full sample. The length of the zero-fundamental period varied across warrants from 3 to 165 days, with an average of 48 days. The only exception is the ShenNeng put warrant, which had no zero-fundamental period but nevertheless expired out of the money. Table 2 also shows that, much like the WuLiang experience, each of the 17 warrants was actively traded with an average daily turnover rate of 328 percent and an average daily volume of 1.29 billion yuan during their respective zero-fundamental periods. The ZhaoHang put warrant even had a one-day volume of 45.68 billion yuan. The return volatility of these put warrants averaged at 271 percent per annum and went to as high as 2,297 percent per annum on a single day for the WuGang put warrant.

Table 2 shows that 14 of the 18 warrants violated the fundamental upper bound implied by the daily stock price drop limit. In addition, two put warrants' prices exceeded their respective strikes - this occurred on three trading days for HuaLing and two trading days for WuLiang.

Interestingly, for a majority of the deep-out-of-the-money put warrants, the listing exchange (either SHSE or SZSE) had made at least one public announcement, in some cases multiple ones on different dates, cautioning investors of the large difference between the current stock price and the warrant's strike price. ${ }^{14}$ Since exchange announcements are usually widely disseminated by brokerage firms among investors, they make the rise of the warrants bubble even more striking.

\section{Maturity Effects}

Each warrant has a predetermined last trading date. How does the approaching of the last trading date affect warrants market dynamics? We analyze this question by focusing on the sample of the 17 put warrants in their zero-fundamental periods. As we discussed before, in each warrant's zero-fundamental period, it has an economically negligible fundamental value, and thus its price approximates the price bubble. We call this data sample the bubble sample, which will be the primary focus of our analysis from now on.

Figure 3 plots the warrants' price bubble and return volatility, averaged across the 17 warrants in the bubble sample, with respect to the number of trading days

\footnotetext{
${ }^{12}$ One-year rolling stock return volatility is used to define the zero-fundamental period. For robustness, we also employed a perfect foresight measure of volatility from the daily returns of each underlying stock between October 16, 2007 and November 4, 2008, when the China Securities Index CSI 300 fell from its peak level of 5,877 to 1,628. All the results that build on the zero-fundamental periods remain similar throughout the paper and are unreported for brevity.

${ }^{13}$ One of the warrants, JiChang, has a long exercise period, which partially overlaps with its trading period. We have used a binomial-tree method to compute its Black-Scholes value, rather than directly applying the BlackScholes formula.

${ }^{14}$ These announcements are archived on the exchange websites.
} 
Table 2-Market Dynamics during the Zero-Fundamental Period

\begin{tabular}{|c|c|c|c|c|c|c|c|c|}
\hline \multicolumn{3}{|c|}{ Panel A. Warrant price and trading volume } & \multicolumn{2}{|c|}{ Warrant price } & \multicolumn{2}{|c|}{ Daily turnover (percent) } & \multicolumn{2}{|c|}{ Yuan volume (million) } \\
\hline Name & First day, last day & Days & Average & Maximum & Average & Maximum & Average & Maximum \\
\hline $\begin{array}{l}\text { WanKe } \\
\text { ShenNeng }\end{array}$ & $8 / 3 / 2006,8 / 28 / 2006$ & $\begin{array}{c}17 \\
0\end{array}$ & 0.055 & 0.09 & 178 & 547 & 176 & 317 \\
\hline WuGang & $11 / 6 / 2006,11 / 15 / 2006$ & 7 & 0.188 & 0.281 & 765 & 1,695 & 756 & 1,451 \\
\hline JiChang & $12 / 6 / 2006,12 / 15 / 2006$ & 6 & 0.721 & 0.96 & 378 & 725 & 767 & 1,334 \\
\hline YuanShui & $1 / 24 / 2007,2 / 5 / 2007$ & 9 & 0.379 & 0.562 & 510 & 1,471 & 711 & 2,589 \\
\hline HuChang & $1 / 10 / 2007,2 / 27 / 2007$ & 30 & 0.586 & 0.924 & 264 & 991 & 751 & 2,162 \\
\hline BaoGang & $2 / 13 / 2007,3 / 23 / 2007$ & 24 & 0.448 & 0.588 & 296 & 1,406 & 1,000 & 2,621 \\
\hline WanHua & $1 / 9 / 2007,4 / 19 / 2007$ & 67 & 1.014 & 1.39 & 183 & 1,438 & 299 & 1,700 \\
\hline GangFan & $3 / 13 / 2007,4 / 24 / 2007$ & 27 & 0.843 & 1.25 & 237 & 1,316 & 364 & 881 \\
\hline HaiEr & $12 / 4 / 2006,5 / 9 / 2007$ & 89 & 0.614 & 0.826 & 96 & 1,072 & 353 & 1,280 \\
\hline YaGe & $2 / 12 / 2007,5 / 14 / 2007$ & 55 & 0.544 & 0.749 & 145 & 972 & 433 & 1,250 \\
\hline MaoTai & $4 / 16 / 2007,5 / 22 / 2007$ & 19 & 0.41 & 0.71 & 289 & 815 & 523 & 1,875 \\
\hline JiaFei & 4/9/2007, 6/22/2007 & 44 & 1.97 & 6.07 & 363 & 1,741 & 1,285 & 7,990 \\
\hline ZhaoHang & $12 / 18 / 2006,8 / 24 / 2007$ & 165 & 0.628 & 3.269 & 180 & 1,198 & 6,384 & 45,683 \\
\hline ZhongJi & $5 / 22 / 2007,11 / 16 / 2007$ & 111 & 3.034 & 7.12 & 312 & 1,662 & 3,680 & 17,053 \\
\hline HuaLing & $9 / 13 / 2007,2 / 22 / 2008$ & 40 & 1.768 & 3.87 & 246 & 1,306 & 1,428 & 3,907 \\
\hline WuLiang & $7 / 23 / 2007,3 / 26 / 2008$ & 150 & 2.815 & 5.218 & 210 & 1,841 & 1,286 & 4,974 \\
\hline NanHang & $6 / 11 / 2008,6 / 13 / 2008$ & 3 & 0.093 & 0.172 & 926 & 1,261 & 1,694 & 2,677 \\
\hline Average & & 48 & 0.948 & 2.003 & 328 & 1,262 & 1,288 & 5,867 \\
\hline Average(fir & & 21 & 0.529 & 0.756 & 351 & 1,199 & 603 & 1,632 \\
\hline Average (las & & 75 & 1.320 & 3.112 & 307 & 1,319 & 1,896 & 9,632 \\
\hline Difference & & 54 & 0.790 & 2.356 & -44 & 120 & 1,293 & 8,000 \\
\hline$p$-value & & 0.016 & 0.059 & 0.019 & 0.691 & 0.526 & 0.070 & 0.118 \\
\hline
\end{tabular}

Notes: Panel A shows, for each warrant, the sample period of zero fundamental value defined by its Black-Scholes value at the end of each trading day being less than 0.0005 yuan (half of the minimum trading tick), or for cashsettled NanHang if the settlement price will for sure exceed the strike. The Black-Scholes value is computed using the previous one year's daily return volatility. Panel A reports, for each warrant in its zero-fundamental period, the time-series average/maximum of its daily closing price, daily turnover, and daily trading volume (in million yuan). For each warrant in its zero-fundamental period, panel B reports the time-series average/maximum of its daily 5-minute return volatility (annualized), the pairwise daily return correlation between the warrant and its underlying stock, and the skewness coefficient of the daily warrant return. The $p$-value for the null hypothesis of zero skewness is calculated using the Pearson Type VII curve approximation in Ralph D'Agostino and Gary Tietjen (1973) which requires at least 8 daily return observations. Panel B also shows, for each warrant, the number of days its closing price is higher than the fundamental upper bound computed by assuming its underlying stock price drops 10 percent every day before expiration (maximum daily drop allowed in China's stock market), and the time-series average of the yuan amount that the closing price surpasses the upper bound when the bound is violated. Cross-sectional averages for all warrants, for the first 9 warrants, and for the last 9 warrants are reported along with the $p$-values for testing the null hypothesis of no difference between the first 9 and last 9 warrants.

(Continued)

remaining. An interesting pattern is that while there is a clear downward trend in the price as the last trading day approaches, the price drop is gradual, i.e., there is not any dramatic crash down to zero before the end. The price moves from an average of around 1.2 yuan when there are 50 trading days remaining down to 0.7 yuan when there are six trading days remaining. The price drop speeds up during the last few trading days, with the price eventually ending in pennies at the end of the last trading day. The price volatility gradually increases from 100 percent per annum when there are still 50 trading days remaining to over 200 percent when there are six trading days remaining and shoots further up in the last few days to 1,400 percent at the end.

Figure 3 also plots the warrants' daily turnover rate and yuan volume, averaged across the 17 warrants in the bubble sample, with respect to the number of trading days remaining. The daily turnover rate gradually increases from about 100 percent when there are still 50 trading days remaining to about 400 percent when there are only six trading days remaining and eventually shoots up to over 1,000 percent on 
Table 2-Market Dynamics during the Zero-Fundamental Period (Continued)

\begin{tabular}{|c|c|c|c|c|c|c|c|c|}
\hline \multicolumn{9}{|c|}{ Panel B. Warrant volatility, correlation with stock, skewness, and violation of price bound } \\
\hline Name & Average & Maximum & Correlation & $p$-value & Skewness & $p$-value & Days & $\begin{array}{l}\text { Average } \\
\text { magnitude }\end{array}$ \\
\hline WanKe & 306 & 1,139 & -0.424 & 0.090 & -1.879 & 0.001 & 1 & 0.001 \\
\hline ShenNeng & & & & & & & 0 & \\
\hline WuGang & 763 & 2,297 & 0.045 & 0.925 & 0.931 & & 0 & \\
\hline JiChang & 278 & 414 & 0.383 & 0.454 & -0.899 & & 0 & \\
\hline YuanShui & 397 & 1,362 & -0.166 & 0.669 & -0.292 & 0.613 & 0 & \\
\hline HuChang & 214 & 1,309 & 0.46 & 0.011 & -2.461 & 0 & 3 & 0.319 \\
\hline BaoGang & 165 & 1,019 & -0.082 & 0.704 & -2.891 & 0 & 5 & 0.225 \\
\hline WanHua & 133 & 1,772 & -0.035 & 0.777 & -2.757 & 0 & 9 & 0.527 \\
\hline GangFan & 173 & 1,438 & -0.435 & 0.023 & -3.069 & 0 & 2 & 0.153 \\
\hline HaiEr & 100 & 1,620 & -0.021 & 0.844 & -4.945 & 0 & 7 & 0.266 \\
\hline YaGe & 122 & 1,433 & 0.006 & 0.967 & -3.747 & 0 & 11 & 0.295 \\
\hline MaoTai & 316 & 2,112 & -0.142 & 0.561 & -1.452 & 0.006 & 7 & 0.123 \\
\hline JiaFei & 300 & 1,669 & 0.003 & 0.983 & 1.703 & 0 & 8 & 2.564 \\
\hline ZhaoHang & 153 & 1,872 & -0.11 & 0.158 & 4.861 & 0 & 13 & 0.264 \\
\hline ZhongJi & 180 & 1,150 & -0.052 & 0.587 & -0.766 & 0.002 & 8 & 0.216 \\
\hline HuaLing & 242 & 1,384 & -0.013 & 0.938 & -1.181 & 0.003 & 8 & 0.256 \\
\hline WuLiang & 131 & 1,475 & 0.094 & 0.251 & -2.954 & 0 & 16 & 0.261 \\
\hline NanHang & 626 & 1,248 & -0.887 & 0.306 & -0.488 & & 6 & 0.165 \\
\hline Average & 271 & 1,454 & -0.081 & 0.289 & -1.311 & 0.033 & 5.8 & 0.403 \\
\hline$\overline{\text { Average(first 9) }}$ & 304 & 1,344 & -0.032 & & -1.665 & & 2.2 & 0.245 \\
\hline Average(last 9) & 241 & 1,551 & -0.125 & & -0.997 & & 9.3 & 0.490 \\
\hline Difference & -63 & 208 & -0.093 & & 0.668 & & 7.1 & 0.245 \\
\hline$p$-value & 0.501 & 0.357 & 0.550 & & 0.555 & & 0.000 & 0.395 \\
\hline
\end{tabular}

the last trading day. The average daily yuan volume displays a different pattern. It fluctuates around 3 billion yuan when there are 40 to 60 trading days remaining, drops to around 1 billion yuan when there are ten to 40 trading days remaining, and then shoots up to over 3 billion yuan when there are only seven trading days remaining. Despite the dramatic increase in the daily turnover rate during the last few trading days, the yuan volume drops to 800 million yuan on the last trading day, because of the large price drop at the end.

The price dynamics on the last trading day provide probably an even sharper way of examining maturity effects. Figure 4 plots the price movement of the WanHua put warrant during its last trading day on April 19, 2007. This warrant was traded on the SHSE with regular trading hours from 9:30AM to 11:30AM in the morning and 1PM to 3PM in the afternoon. Figure 4 displays several interesting features. First, the price of the WanHua put warrant did not have any sudden burst during the last trading day. It started at 34.2 pennies at the opening and gradually moved down to 8.7 pennies at the closing. Second, while there was a clear downward trend in the price, there were also several large price runups during the day. One evident run occurred shortly after the opening from 35 pennies to 44 pennies. The last half hour of trading was even more dramatic. The price quickly rose from seven pennies to near 15 pennies, and then fell back to seven pennies, only to run up again to 14 pennies with only 12 minutes to the closing. The trading eventually closed at a price of 8.7 pennies.

Table 3 summarizes the last-day price dynamics of all 18 put warrants. As we discussed before, all of them expired out of the money, 17 of them had Black-Scholes values less than 0.0005 yuan on the last trading day, and 14 of them had violated the 

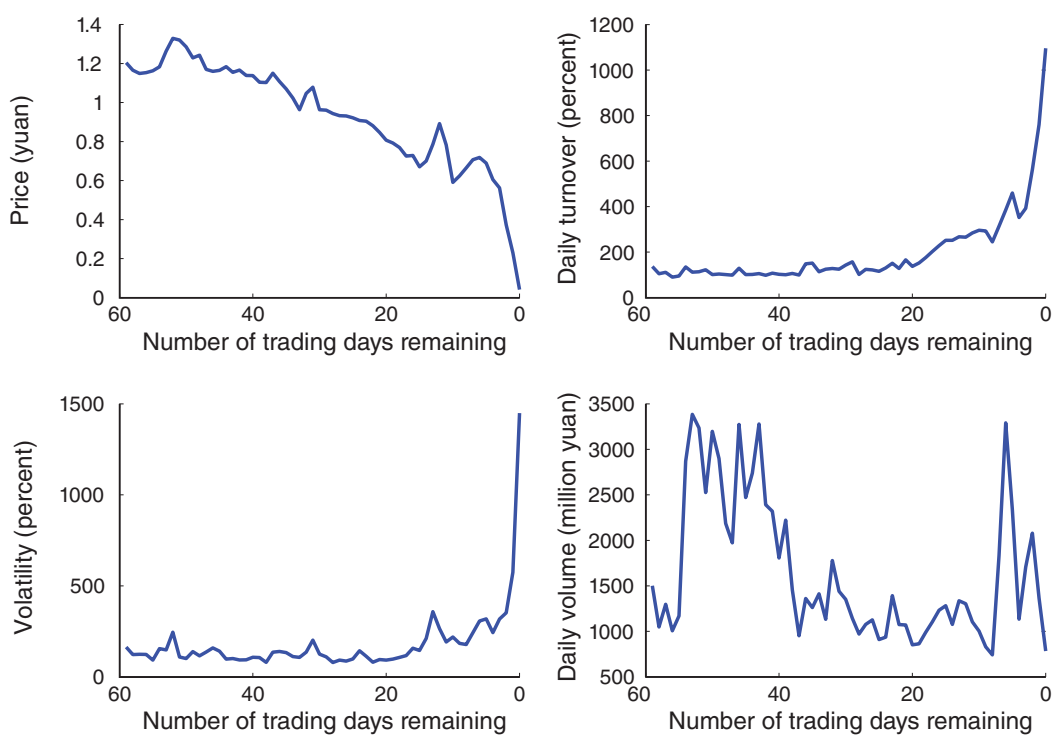

Figure 3. Warrant Dynamics in the Bubble Sample

Notes: This figure shows the average warrant price, the average daily warrant turnover, the average 5-minute warrant return volatility (annualized), and the average daily warrant trading volume (in million yuan) against the number of trading days remaining for the 17 put warrants in the bubble sample. The averaging is across all warrants with a given number of trading days remaining.

fundamental upper bound implied by the 10 percent daily price drop limit. Table 3 shows that each had an extremely active final trading day, just like the WanHua put warrant, with a substantially inflated price and a gradual downward price trend during the day. The average intraday price is 14.9 pennies, and the average closing is 3.9 pennies.

In summary, there are evident maturity effects in the warrants' zero-fundamental periods. As maturity approaches, price gradually declines to zero, accompanied by an increasing trend in return volatility and warrant turnover. While we usually think that a bubble will end with a crash, this warrants bubble only deflates gradually.

\section{The Economic Mechanisms}

What drives the warrant investors to trade so much and pay such inflated prices? In this section, we examine several economic mechanisms. Instead of focusing on one particular theory, we will analyze a set of bubble theories and discuss implications of this data sample for each of these theories.

\section{A. Hedging Premium}

Were the high prices of these put warrants caused by investors' demand to hedge risk in the underlying stocks? Interestingly, Table 2 shows that on average, these put warrants had a small and insignificant return correlation of -0.081 ( $p$-value 0.289 ) with their underlying stocks during their respective zero-fundamental periods. At the individual level, only one of the 18 put warrants, GangFan, had a significantly 


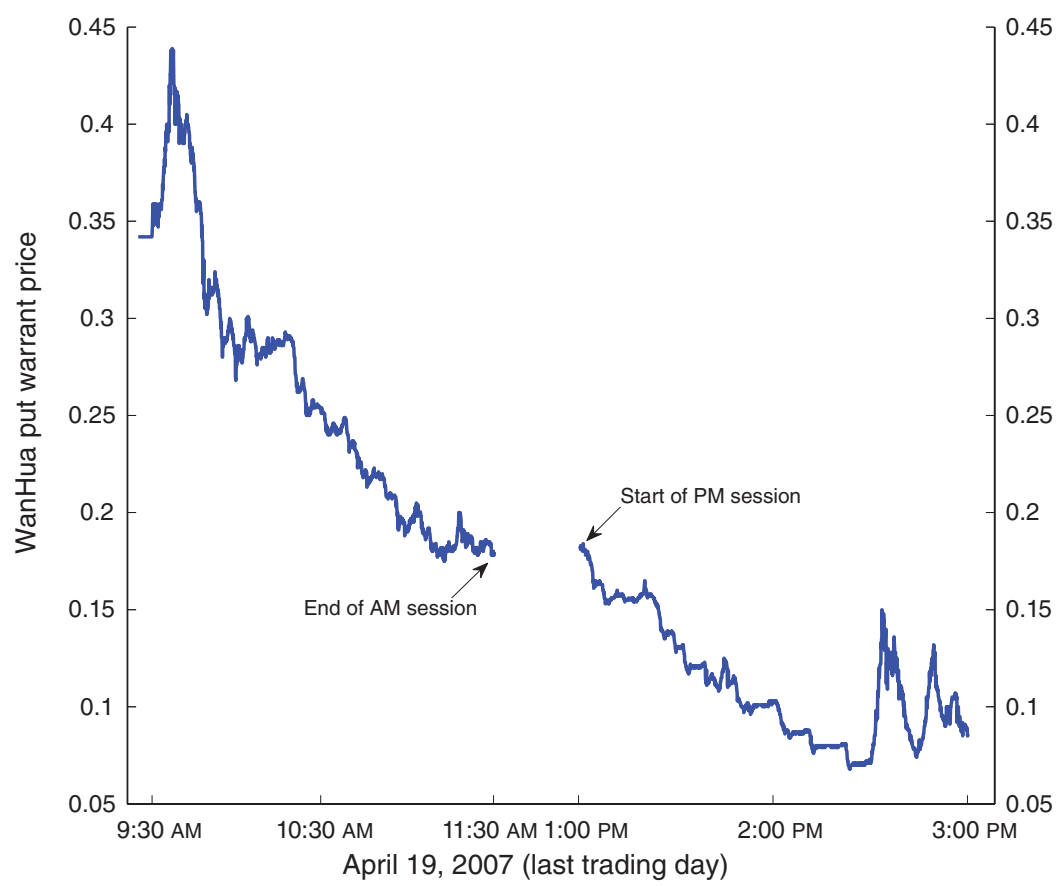

Figure 4. Last-Day Price Dynamics of WanHua Put Warrant

Note: This figure shows the intraday transaction price history of the WanHua put warrant on its last trading day (April 19, 2007).

negative return correlation with its underlying stock. ${ }^{15}$ The lack of return correlation between these warrants and their underlying stocks makes it unlikely that investors trade these warrants to hedge daily fluctuations of the underlying stocks.

Since short sales of stocks are not permitted, stocks may be overvalued by investors who are optimistic about their future fundamentals. Then, stocks may face the risk that one day the overvaluation may be corrected. Put warrants are useful for hedging such jump-to-ruin risk. In particular, a put warrant allows its holder to sell the stock, even when the market halts after the stock price hits the 10 percent daily price drop limit. Suppose that a representative investor holds the warrant throughout its life. Can the premium for jump-to-ruin risk explain the warrant prices? We can show that the magnitude of such a premium is too small. We will analyze the theory building on investors' different beliefs about warrant fundamentals in Section IIIE.

While most of the warrants are settled by selling the underlying stocks to the issuing firms at the strike prices, one of them-NanHang - is cash settled. Precisely, at expiration (June 20, 2008) cash changes hands between warrant holders and the issuing firm based on the arithmetic average of the NanHang stock's daily prices during the

\footnotetext{
${ }^{15}$ In unreported analysis, we find that the return correlation between the warrants and stocks is also small and insignificant during the crash period between October 16, 2007 and November 4, 2008 or in those days during the crash period when the stock return is negative (or less than -0.05 ).
} 
Table 3-Market Dynamics on the Last Trading Day and Irrational Warrant Exercises

\begin{tabular}{|c|c|c|c|c|c|c|c|c|}
\hline \multirow[b]{2}{*}{ Name } & \multicolumn{3}{|c|}{ Intraday price } & \multirow[b]{2}{*}{$\begin{array}{l}\text { Turnover } \\
\text { (percent) }\end{array}$} & \multirow[b]{2}{*}{$\begin{array}{l}\text { Volume } \\
\text { (million) }\end{array}$} & \multirow[b]{2}{*}{$\begin{array}{l}\text { Volatility } \\
\text { (percent) }\end{array}$} & \multicolumn{2}{|c|}{ Exercise } \\
\hline & Close & Average & Maximum & & & & $\begin{array}{c}\text { Exercised } \\
\text { (percent) }\end{array}$ & $\begin{array}{c}\text { Loss } \\
(000)\end{array}$ \\
\hline WanKe & 0.001 & 0.011 & 0.019 & 547 & 98 & 1,139 & 0.08 & 50 \\
\hline ShenNeng & 0.002 & 0.016 & 0.033 & 616 & 40 & 1,449 & 0.01 & 18 \\
\hline WuGang & 0.06 & 0.172 & 0.3 & 1,529 & 1,240 & 2,297 & 0.01 & 31 \\
\hline JiChang & 0.332 & 0.53 & 0.68 & 509 & 699 & 414 & 0.02 & 58 \\
\hline YuanShui & 0.041 & 0.258 & 0.598 & 1,168 & 1,013 & 1,362 & 0.02 & 107 \\
\hline HuChang & 0.015 & 0.209 & 0.442 & 991 & 1,089 & 1,309 & 0.05 & 38 \\
\hline BaoGang & 0.006 & 0.124 & 0.27 & 1,406 & 1,215 & 1,019 & 0.47 & 111 \\
\hline WanHua & 0.087 & 0.187 & 0.441 & 1,438 & 482 & 1,772 & 0.32 & 114 \\
\hline GangFan & 0.01 & 0.147 & 0.32 & 1,316 & 422 & 1,438 & 0.27 & 73 \\
\hline HaiEr & 0.001 & 0.049 & 0.11 & 1,072 & 340 & 1,620 & 0.83 & 581 \\
\hline YaGe & 0.002 & 0.024 & 0.059 & 972 & 159 & 1,433 & 1.18 & 1,667 \\
\hline MaoTai & 0.003 & 0.017 & 0.041 & 801 & 103 & 2,112 & 0.20 & 141 \\
\hline JiaFei & 0.107 & 0.601 & 1 & 1,741 & 1,250 & 1,639 & 0 & 0 \\
\hline ZhaoHang & 0.002 & 0.069 & 0.176 & 968 & 3,036 & 1,872 & 0.02 & 163 \\
\hline ZhongJi & 0.01 & 0.076 & 0.107 & 1,662 & 469 & 1,150 & 0 & 0 \\
\hline HuaLing & 0.01 & 0.093 & 0.15 & 1,306 & 648 & 1,340 & 0 & 0 \\
\hline WuLiang & 0.004 & 0.054 & 0.08 & 1,841 & 285 & 1,475 & 0 & 0 \\
\hline NanHang & 0.003 & 0.044 & 0.099 & 1,261 & 793 & 1,248 & 0 & 0 \\
\hline Average & 0.039 & 0.149 & 0.274 & 1,175 & 743 & 1,449 & 0.19 & 175 \\
\hline Average(first 9) & 0.062 & 0.184 & 0.345 & 1,058 & 700 & 1,355 & 0.14 & 67 \\
\hline Average(last 9) & 0.016 & 0.114 & 0.202 & 1,292 & 787 & 1,543 & 0.25 & 284 \\
\hline Difference & -0.046 & -0.070 & -0.142 & 234 & 87 & 188 & 0.11 & 217 \\
\hline$p$-value & 0.234 & 0.397 & 0.274 & 0.225 & 0.802 & 0.361 & 0.504 & 0.257 \\
\hline
\end{tabular}

Notes: This table reports, for each warrant on its last trading day, the close/average/maximum of its intraday transaction price, the daily turnover, trading volume (in million yuan), and 5-minute warrant return volatility (annualized). Also reported are the fraction of warrant exercised and the total exercise loss (in thousand yuan, assuming the stock price at exercise equals the closing price on the last trading day). Cross-sectional averages for all warrants, for the first 9 warrants, and for the last 9 warrants in the full sample are reported along with the differences between the averages of the first 9 and the last 9 warrants and the $p$-values for testing the null hypothesis of no difference between the first 9 and last 9 warrants.

previous ten trading days (between June 5 and June 19). In other words, the warrant payoff is determined by the difference between its strike price ( 7.43 yuan) and the average stock price. Cash settlement makes the warrant immune from the jump-toruin risk. Thus, we can construct the lowest possible settlement price based on the observed stock price by assuming that the stock price drops 10 percent in each subsequent trading day. For the last six trading days of NanHang warrant (June 6 to 13, 2008), the NanHang stock's closing prices are 10.63, 10.35, 9.32, 8.84, 8.61, and 8.48, which imply that the highest possible warrant payoffs are $0.51,0.03,0.02,0,0$, and 0 , respectively. However, these upper bounds are violated—warrant closing prices are $0.615,0.446,0.211,0.172,0.103$, and 0.003 on these six days.

More generally, the closing price of each warrant at the end of its last trading day allows us to estimate the premium for jump-to-ruin risk. Each warrant expires five business days after the end of its trading period. As a put warrant still protects its holder during this period, its price at the end of the trading period measures the premium for jump-to-ruin risk assessed by its holder. As we will discuss in Section IIIF, the end-of-trading-period price may also reflect possible pricing errors of naïve investors. By ignoring this possibility here, we potentially overestimate the premium for jump-to-ruin risk. 
Table 4 lists the end-of-trading-period prices of 16 put warrants. We exclude NanHang, which is cash settled, and ShenNeng, the only put warrant without a zerofundamental period. The table shows that the end-of-trading-period prices average 4.3 pennies. This low average contrasts with the average warrant prices during the earlier trading days (Figure 3).

We can extrapolate the end-of-trading-period price of each warrant backward to estimate the fraction of its earlier prices that can be attributed to the premium for jump-to-ruin risk. We make several simple but reasonable assumptions to facilitate this estimation. First, we suppose that the jump-to-ruin risk is difficult to predict and, as a result, the perceived jump intensity stays constant over time. Suppose the jump intensity is $k$ per day; then the accumulated jump probability over $T$ days is $1-\exp (-k T)$, which can be linearly approximated by $k T$. This linear approximation works well when $T$ is small but overestimates the jump probability when $T$ is large. Second, once a jump occurs, its magnitude is substantial so that concerns about such a jump are not sensitive to daily stock price fluctuations (as consistent with the lack of correlation between the put warrants and underlying stocks) but can nevertheless lead to a meaningful premium for a deep out-of-the-money put warrant. Under this condition, the jump risk premium per day remains stable over time. Thus, we can linearly extrapolate the end-of-trading-period price of a warrant backward to estimate the premium for jump-to-ruin risk during the earlier trading days. Note that this extrapolation method builds on the assumption that the same representative investor holds the warrant throughout its life.

Table 4 calculates the jump risk premium per day $J$ as the warrant's end-of-trading-period price $P_{0}$ divided by $T$, the number of business days between its last trading day and expiration day. The average jump risk premium across the 16 warrants is 0.9 penny per day. Then, on an earlier day with t trading days remaining the warrant price attributable to jump risk $V_{t}$ is estimated to be $V_{t}=(T+t) J$ and the fraction of the price unexplained by jump risk is $\left(P_{t}-V_{t}\right) / P_{t}$ where $P_{t}$ is the traded warrant price when there are $t$ trading days remaining. (Note that this linear extrapolation overestimates the jump premium if $\mathrm{t}$ is large.) Table 4 reports this fraction for each warrant when there are fewer than ten trading days remaining. The premium for jump risk explains only a small fraction of the warrant prices. The unexplained fraction across the 16 warrants remains stable between 81 and 87 percent during these ten days. The $t$-test significantly rejects the hypothesis that the unexplained fraction is zero for each of the days.

\section{B. Rational Bubbles}

Economists have made many attempts to explain price bubbles in settings with only rational agents. Blanchard and Watson (1983) provide an example of rational bubbles in a discrete-time model with homogenous rational investors and infinite periods. In each period, a bubble component in asset prices grows on average at the same rate as the discount rate. This mechanism cannot explain the warrants bubble because warrants have finite maturities, and rational investors' backward induction should rule out any bubble of this type in the earlier periods. In this sense, the warrants bubble is special as it shows that bubbles can emerge on assets with predetermined finite maturities. 
Table 4-Fraction of Warrant Price Unexplained by Jump-to-Ruin Risk

\begin{tabular}{|c|c|c|c|c|c|c|c|c|}
\hline \multirow{2}{*}{$\begin{array}{l}\text { Remaining trading } \\
\text { days }\end{array}$} & \multicolumn{6}{|c|}{ Fraction of warrant price unexplained by jump risk } & \multirow{2}{*}{$\begin{array}{l}\text { Warrant last } \\
\text { close }\end{array}$} & \multirow{2}{*}{$\begin{array}{l}\text { Jump } \\
\text { premium }\end{array}$} \\
\hline & 1 & 2 & 3 & 4 & 5 & 10 & & \\
\hline GangFan & 0.96 & 0.97 & 0.98 & 0.98 & 0.97 & 0.95 & 0.01 & 0.002 \\
\hline WanKe & 0.94 & 0.96 & 0.96 & 0.95 & 0.95 & 0.96 & 0.001 & 0.0002 \\
\hline HuaLing & 0.92 & 0.92 & 0.91 & 0.91 & 0.90 & 0.85 & 0.01 & 0.002 \\
\hline WuLiang & 0.94 & 0.96 & 0.97 & 0.97 & 0.97 & 0.97 & 0.004 & 0.0008 \\
\hline ZhongJi & 0.89 & 0.91 & 0.91 & 0.90 & 0.93 & 0.95 & 0.01 & 0.002 \\
\hline JiaFei & 0.76 & 0.89 & 0.96 & 0.95 & 0.96 & 0.90 & 0.107 & 0.0214 \\
\hline MaoTai & 0.93 & 0.96 & 0.97 & 0.97 & 0.98 & 0.98 & 0.003 & 0.0006 \\
\hline HaiEr & 0.99 & 0.99 & 0.99 & 0.99 & 0.99 & 0.99 & 0.001 & 0.0002 \\
\hline YaGe & 0.96 & 0.98 & 0.99 & 0.99 & 0.99 & 0.99 & 0.002 & 0.0004 \\
\hline WanHua & 0.71 & 0.83 & 0.79 & 0.78 & 0.79 & 0.61 & 0.087 & 0.0174 \\
\hline YuanShui & 0.89 & 0.80 & 0.81 & 0.80 & 0.80 & 0.79 & 0.041 & 0.0082 \\
\hline BaoGang & 0.98 & 0.98 & 0.98 & 0.97 & 0.97 & 0.96 & 0.006 & 0.0012 \\
\hline HuChang & 0.96 & 0.96 & 0.95 & 0.94 & 0.93 & 0.90 & 0.015 & 0.003 \\
\hline ZhaoHang & 0.98 & 0.99 & 0.99 & 0.98 & 0.99 & 0.96 & 0.002 & 0.0004 \\
\hline JiChang & 0.35 & 0.28 & 0.38 & 0.32 & 0.28 & -0.09 & 0.332 & 0.0664 \\
\hline WuGang & 0.36 & -0.47 & 0.36 & 0.53 & 0.56 & 0.35 & 0.06 & 0.012 \\
\hline Average & 0.84 & 0.81 & 0.87 & 0.87 & 0.87 & 0.81 & 0.043 & 0.009 \\
\hline$t$-stat for fraction $=0$ & 16.44 & 8.43 & 17.08 & 18.42 & 18.00 & 11.03 & & \\
\hline
\end{tabular}

Notes: This table shows the fraction of warrant price unexplained by jump risk premium. For each warrant, the jump risk premium per day, denoted $J$, is set to its price at the close of its last trading day (denoted by $P_{0}$ ) divided by the number of business days after the last trading day but before the expiration of warrant exercise (denoted by $T$ ), i.e., $J=P_{0} / T . T=5$ for all the warrants in the sample. Then, the warrant price attributable to jump risk during a warrant trading day is computed as $V_{t}=(T+t) J$ where $t$ is the number of trading days remaining. The fraction of warrant price unexplained by such jump risk premium is shown for each warrant (excluding NanHang and ShenNeng) when there are up to 10 trading days remaining. The fraction is computed as $\left(P_{t}-V_{t}\right) / P_{t}$, where $P_{t}$ is the warrant price when there are $t$ trading days remaining.

\section{Agency Problems}

Allen and Gorton (1993) and Allen and Gale (2000) develop models to show that bubbles can arise from agency problems of institutions. In the presence of asymmetric information and contract frictions between portfolio managers and investors who hire them, managers have incentives to churn and seek risk at the expense of their investors. As a result, assets can trade at prices that do not reflect their fundamentals. While institutional asset management had rapid growth in China during the recent years, the size of this industry is still small relative to the size of China's financial markets. More importantly, most institutions had stayed out of the warrants market, perhaps because of the overvaluation and extreme volatility. The Shanghai stock exchange publishes on its Web site the weekly fraction of the total yuan volume contributed by institutions for all warrants traded on the SHSE from June 2006 (when the exchange started to publish the data) to June 2008 (the end of our warrant sample). This fraction is small throughout. It hit between 1 and 2 percent for some brief periods in 2006 and then mostly stayed at levels around 0.2 percent. Given their limited presence in the warrants market, it is unlikely that agency problems of institutions are a key driver of the warrants bubble.

\section{Gambling Behavior}

Investors may treat warrants like lottery tickets. Gamblers prefer a lottery ticket despite its unfavorable odds because of its positively skewed payoff, i.e., the payoff 
can either take a large positive value with a small probability or a small negative value with a large probability. Several economic theories suggest that investors might have a similar risk preference towards financial investment and cause assets with positive skewness to be overvalued. Barberis and Huang (2008) develop such a theory based on a behavioral bias that when evaluating risk, people tend to overweigh tails of the distribution. Brunnermeier, Christian Gollier, and Jonathan Parker (2007) also propose a theory based on the idea that agents derive utility not only from consumption but also from anticipation of future consumption.

Are warrants lottery tickets? Table 2 shows that for the daily returns, 14 of the 18 warrants have negative return skewness in their zero fundamental periods with an average of -1.311 and a significant $p$-value of 0.033 . ${ }^{16}$ In unreported results, skewness of the five-minute intraday warrant returns also tends to be negative. The lack of evidence of positive skewness in both intraday and daily warrant returns refutes gambling behavior as an explanation of the warrants bubble.

\section{E. The Resale Option Theory}

Harrison and Kreps (1978) propose a theory of asset bubbles based on the joint effects of short-sales constraints and heterogeneous beliefs. When short sales of assets are constrained and investors hold heterogeneous beliefs about an asset's fundamentals, asset prices are biased toward the optimists' belief because pessimists cannot short sell and will only sit on the sideline. More importantly, Harrison and Kreps show that if beliefs fluctuate over time, an optimist is willing to pay more than his already optimistic belief of asset fundamentals, anticipating the possibility to resell the asset in the future to an even more optimistic investor. This resale option can drive price higher than the most optimistic belief by any investor and thus forms a bubble. This theory, which is sometimes referred to as the resale option theory, captures several important features of China's warrants market.

Short-sales constraints are clearly present in China's warrants market, as it is illegal for investors to short warrants. While the SHSE had set up a creation program to allow a group of designated brokerage firms to issue warrants on the SHSE, as we discussed in Section I, the scope of this creation program was limited, and the creation force was too feeble to cool off the warrants bubble.

Despite that warrants derive fundamentals from the publicly observable underlying stock prices, investors can still hold different beliefs about the warrant fundamentals because valuing warrants requires beliefs about the future price dynamics of the underlying stocks. In particular, to value the deep-out-of-the-money put warrants in our sample, investors need to form beliefs about the stock prices' tail distributions, which are difficult to estimate based on past prices. Thus, it is plausible that some investors assign a higher probability to a stock's jump-to-ruin risk (possibly because of their pessimistic belief about the stock fundamentals), while some others believe such risk is minimal. ${ }^{17}$ The investors' beliefs can also fluctuate over time

\footnotetext{
${ }^{16}$ We also examined the return skewness after excluding the last trading day, during which warrant prices usually experience dramatic drops to near-zero levels. While the skewness increases after excluding the last trading day, there is still no evidence for positive skewness.

${ }^{17}$ Allen, Morris, and Andrew Postlewaite (1993) derive a model in which asymmetric information about asset fundamentals can generate higher-order heterogeneous beliefs. It is unlikely for investors to possess asymmetric
} 
with changes in the stock prices and arrivals of new information. Such belief fluctuations can in turn generate speculative trading among the investors and motivate a warrant buyer to pay a price higher than his own valuation.18

Scheinkman and Xiong (2003) develop a model in which overconfident investors overweigh their respective favorite signals in inferring an asset's fundamental value. The different learning schemes lead to a time-varying difference of beliefs among investors, which in turn stimulates speculative trading. This model was not developed to analyze the warrants market, because it does not incorporate investors' beliefs about tail distribution, which are important for valuing deep-out-of-themoney put warrants. Thus, matching the quantitative aspects of this model with the warrants bubble requires modifications of investors' belief dynamics. But we expect the qualitative implications of the model to be nevertheless applicable to the warrants market. In particular, the model shows that the more the difference in beliefs fluctuates, the more intensively investors trade with each other, and, at the same time, the more they are willing to pay for the option to resell the asset to others. In this way, the model provides an interesting prediction that the magnitude of the price bubble is positively correlated with trading frequency.

In our empirical analysis, we first examine whether there is a positive correlation between warrant price and trading volume. We pool together the daily closing prices of the 18 put warrants in their zero fundamental periods according to their time-tomaturities (number of trading days remaining). Because of the negligible warrant fundamentals during the sample, warrant prices approximate the bubble size. Table 5 provides various panel regressions of the warrant prices. Since there is a strong maturity effect in prices, we include a maturity fixed effect in these regressions. ${ }^{19}$ In regression (1) of Table 5, we regress warrant price on daily turnover rate,

$$
\text { (1) } \text { PRICE }_{i, t}=b_{0}+b_{1} \cdot \text { TURNOVER }_{i, t}+\text { MATURITY FIXED EFFECT }+e_{i, t} \text {. }
$$

$P R I C E_{i, t}$ is the closing price of warrant $i$ on day $t$, which is indexed by the number of trading days remaining, and $e$ is a generic term capturing sampling noise. The coefficient of interest is $b_{1}$ in front of the daily turnover measure TURNOVER $R_{i, t}$. This coefficient is pinned down by the cross-sectional differences between different warrants after controlling for the maturity fixed effect. Its estimate is positive and significant with a $t$-statistic of 8.91 , confirming a positive correlation between the size of price bubble and turnover rate.

Another implication of Scheinkman and Xiong (2003) is that size of a bubble is positively correlated with its volatility. When the warrant prices are more volatile, investors' beliefs about their future prices tend to fluctuate more, and the resale

\footnotetext{
information about the underlying stock prices as they are publicly observable. However, it is possible for investors to hold asymmetric information about the stocks' jump-to-ruin risk. It is probably even more realistic that they use different models to value warrants based on the publicly observable underlying stock prices.

${ }^{18}$ Heterogeneous beliefs can also arise from another type of heterogeneity among investors. As we will discuss in Section IIIF, some of the warrant investors were inexperienced and confused put warrants with call warrants, while some others were smart. This difference in investor sophistication could have led to the use of opposite pricing models for those put warrants and hence heterogeneous beliefs about warrant fundamentals.

${ }^{19}$ The maturity fixed effect prevents spurious correlation related to the time trends in the warrant price, turnover, and volatility as the warrant expiration approaches. In fact, this fixed-effect regression is equivalent to a detrended regression where the left-hand-side and right-hand-side variables are de-meaned by matching warrants with the same time-to-maturity (e.g., chapter 14.3 of William H. Greene 1997).
} 
Table 5-Determinants of Size of the Warrants Bubble

\begin{tabular}{|c|c|c|c|c|c|c|}
\hline & (1) & (2) & (3) & (4) & (5) & (6) \\
\hline $\begin{array}{l}\text { TURNOVER } \\
\quad(t \text {-stat })\end{array}$ & $\begin{array}{c}0.203 \\
(8.91)\end{array}$ & & & $\begin{array}{c}0.158 \\
(5.46)\end{array}$ & & $\begin{array}{l}0.105 \\
(3.80)\end{array}$ \\
\hline $\begin{array}{l}V O L \\
\quad(t \text {-stat })\end{array}$ & & $\begin{array}{l}21.76 \\
(5.38)\end{array}$ & & $\begin{array}{l}14.12 \\
(2.97)\end{array}$ & & $\begin{array}{l}13.99 \\
(3.05)\end{array}$ \\
\hline $\begin{array}{l}\text { FLOAT } \\
\quad(t \text {-stat })\end{array}$ & & & $\begin{array}{l}-0.302 \\
(12.62)\end{array}$ & $\begin{array}{l}-0.324 \\
(12.31)\end{array}$ & & \\
\hline $\begin{array}{l}\text { FIRMISSUE } \\
\quad(t \text {-stat })\end{array}$ & & & & & $\begin{array}{l}-1.302 \\
(25.03)\end{array}$ & $\begin{array}{l}-1.260 \\
(23.53)\end{array}$ \\
\hline $\begin{array}{l}\text { BROKERAGEISSUE } \\
\quad(t \text {-stat })\end{array}$ & & & & & $\begin{array}{c}0.496 \\
(15.84)\end{array}$ & $\begin{array}{r}0.419 \\
(12.60)\end{array}$ \\
\hline
\end{tabular}

Notes: This table includes the regression results of daily warrant closing prices on TURNOVER (daily warrant turnover) in column 1, on VOL (5min warrant return volatility) in column 2, on FLOAT (the total number of warrants outstanding, in billions) in column 3, on TURNOVER, VOL, and FLOAT together in column 4, on FIRMISSUE (the total amount of warrants issued by the underlying firm from Table 1, in billions) and BROKERAGEISSUE (net total warrant issued by brokerage firms, in billions) in column 5, and on TURNOVER, VOL, FIRMISSUE, and BROKERAGEISSUE together in column 6. The regressions use the zero-fundamental sample (defined as BlackScholes value less than 0.0005 , or for cash-settled NanHang if the settlement price will for sure exceed the strike) and include warrant maturity fixed effect. The $t$-statistics, in the parentheses, are adjusted for heteroskedasticity and correlation within a trading day.

option is thus more valuable. Note that this prediction is opposite to the standard asset pricing theories, which typically predict a negative correlation between asset price and volatility because of the trade-off between risk and expected returns. ${ }^{20}$ In regression (2) of Table 5, we regress warrant price on warrant return volatility,

$$
\text { PRICE }_{i, t}=c_{0}+\mathrm{c}_{1} \cdot \text { VOL }_{i, t}+\text { MATURITY FIXED EFFECT }+e_{i, t} .
$$

$V O L_{\mathrm{it}}$ is the return volatility of warrant $i$ on day $t$ constructed from five-minute intraday returns. The coefficient of interest is $c_{1}$ in front of the volatility. The coefficient is again positive and significant with a $t$-statistic of 5.38 .

Hong, Scheinkman, and Xiong (2006) develop a model to show that asset float (number of tradable shares) has a large effect on the size of bubble. When investors have a limited risk-bearing capacity, a larger float implies that it takes a greater difference between the optimists' and pessimists' beliefs for optimists to drive out pessimists. This implies that it takes a greater belief divergence in the future for an existing asset holder to resell profitably, which in turn makes the resale option less valuable today. In regression (3) of Table 5, we examine the relationship between asset float and the warrants price,

$$
\text { (3) } \text { PRICE }_{i, t}=d_{0}+d_{1} \cdot \text { FLOAT }_{i, t}+\text { MATURITY FIXED EFFECT }+e_{i, t} \text {. }
$$

$F_{L O A T}$ is the total number of warrants outstanding for warrant $i$ on day $t$. The coefficient of interest is $d_{1}$ in front of the float. The coefficient is negative and highly

\footnotetext{
${ }^{20}$ Pastor and Veronesi (2003) present an exception by showing that the value of a firm with a persistent growth rate can increase with uncertainty about its future growth rate due to a convexity effect in the firm's valuation. This insight does not apply to the warrants because of their finite maturities and the lack of persistent growth.
} 
significant with a $t$-statistic of 12.62 , confirming the prediction that price bubble is negatively related to asset float.

We also combine turnover rate, volatility, and float in a single regression-column 4 of Table 5. Each variable has a similar effect on the size of warrants bubble as in the individual regressions.

Note that the number of tradable shares of the warrants traded on the SHSE changes over time because of the exchange's share creation program. The working paper version of this article (NBER working paper \#15481) provides a summary of the number of shares issued by the designated brokerage firms for the 11 SHSE-traded warrants. Because of the tight control by the SHSE, the shares issued by the brokerage firms in the secondary market for most warrants are small relative to the initial shares, although two warrants (WanHua and ZhaoHang) had more shares issued by the brokerage firms at some points in time. To control for the effect of the time-varying float, we decompose the total float into the initial float and the net new issuance and then repeat regressions (3) and (4) of Table 5 using the decomposed float variables. As reported in columns 5 and 6 of Table 5, the warrant price is negatively correlated with the initial float but positively correlated with the net new issuance, and both coefficients are statistically significant. The positive correlation between the warrant price and the net new issuance shows that the designated brokerage firms tend to issue more shares when warrant prices are high. 211 The negative effect of the initial float on the warrant price remains the same as that in columns 3 and 4 of Table 5.

Overall, Table 5 provides a set of regression results supporting various predictions of the resale option theory. The positive correlation between the warrant price and turnover rate corroborates a similar observation about many historical bubbles, such as the tulip mania in seventeenth-century Holland, the stock market bubble before the 1929 great crash, and more recently the Internet bubble in the late 1990s, e.g., John Cochrane (2003) and Hong and Jeremy C. Stein (2007). This finding is also consistent with Mei, Scheinkman, and Xiong (2009), who show that speculative trading by domestic investors helps explain the stock price differential between the A- and B-shares (i.e., the domestic and foreign shares) of the same Chinese firms before the segmentation of these two classes of shares was gradually liberated in the early 2000s. This positive correlation also justifies trading frenzy as a measure of investor sentiment, e.g., Malcolm Baker and Jeffrey Wurgler (2007). The negative correlation between warrant price and asset float is also consistent with the finding of Ofek and Richardson (2003) that the large increase of float in the early 2000s after the lockup expirations of many Internet firms is an important driving factor for the burst of the Internet bubble.

The resale option theory also has a direct implication for the effect of asset maturity on price bubble. As demonstrated by Hong, Scheinkman, and Xiong (2006) in a model with multiple rounds of trading, the value of an asset holder's resale option decreases if there are fewer rounds left and thus fewer opportunities for reselling his asset for a speculative profit. Thus, as the warrant maturity approaches, a buyer

\footnotetext{
${ }^{21}$ By examining the time series of each individual brokerage firm's issuance, we find no evidence of short squeeze. Instead, the issuance generally increases with the price bubble, consistent with the regression result in Table 5.
} 
values the resale option less. In this way, this model prediction explains the gradual decline in the warrant prices before and during the last trading day.

Figure 5 plots the cross-sectional average daily percentage drop in warrant price against the number of trading days remaining. The figure shows that, while the price drop is relatively stable in the earlier period, it intensifies during the last eight trading days, indicating a higher resale option value associated with each of these days near expiration.

What explains the higher resale option value near expiration? Recall Figure 3, which shows that the warrants tend to become more speculative near expirationthe share turnover and return volatility of the warrants both shoot up during the last several trading days, especially on the last day. Interestingly, once the daily warrant price drop is scaled by the corresponding daily turnover rate or warrant return volatility, it becomes rather stable across maturity. This suggests that the higher resale option value in the last several days is related to the intensified trading at the end.22

\section{F. Noncommon Knowledge of Rationality}

Due to the difficulty in measuring asset fundamentals in field data, most empirical analyses of asset bubbles are carried out in experimental studies. The Chinese warrants bubble confirms several important findings of the experimental studies and permits an analysis of the key hypothesis on noncommon knowledge of rationality, which is widely employed in this literature.

A key finding of the experimental literature is that bubbles can arise even when asset fundamentals are publicly observable and asset maturities are finite. This phenomenon was first discovered by the classic study of Smith, Suchanek, and Williams (1988) and since then has been replicated in many other studies, e.g., Porter and Smith (1995); Lei, Noussair, and Plott (2001); Dufwenberg, Lindqvist, and Moore (2005); Ackert et al. (2006); Haruvy and Noussair (2006); Haruvy, Lahav, and Noussair (2007); Hirota and Sunder (2007); and Hussam, Porter, and Smith (2008), under a variety of treatments. As is typical in these studies, markets are created for traders to trade dividendpaying assets with a lifetime of a finite number of periods. The only source of asset fundamentals is dividends, whose distributions are publicly announced to all traders. A common finding in these experimental studies is that the assets are often traded in high volumes at prices substantially above the fundamental values.

The warrants in our sample also have finite maturities with final payoffs determined by the underlying stock prices, which are publicly observable to all market participants. While deriving expected warrant payoffs at expiration requires a belief about future dynamics of the stock prices, our analysis in Section IIIA shows that the traded warrant prices were too high to be justified by any reasonable belief of a representative investor. Our analysis in the previous subsection further confirms a positive correlation between the warrants bubble and trading volume. The experimental studies have also identified short-sales constraints as a crucial factor

\footnotetext{
${ }^{22}$ The intensified trading at the end may reflect more volatile belief dispersion among the warrant investors near warrant expirations. Because of the lack of account-level trading data, we will leave a more elaborate analysis of the participants of the warrant markets and their behavior for future studies.
} 

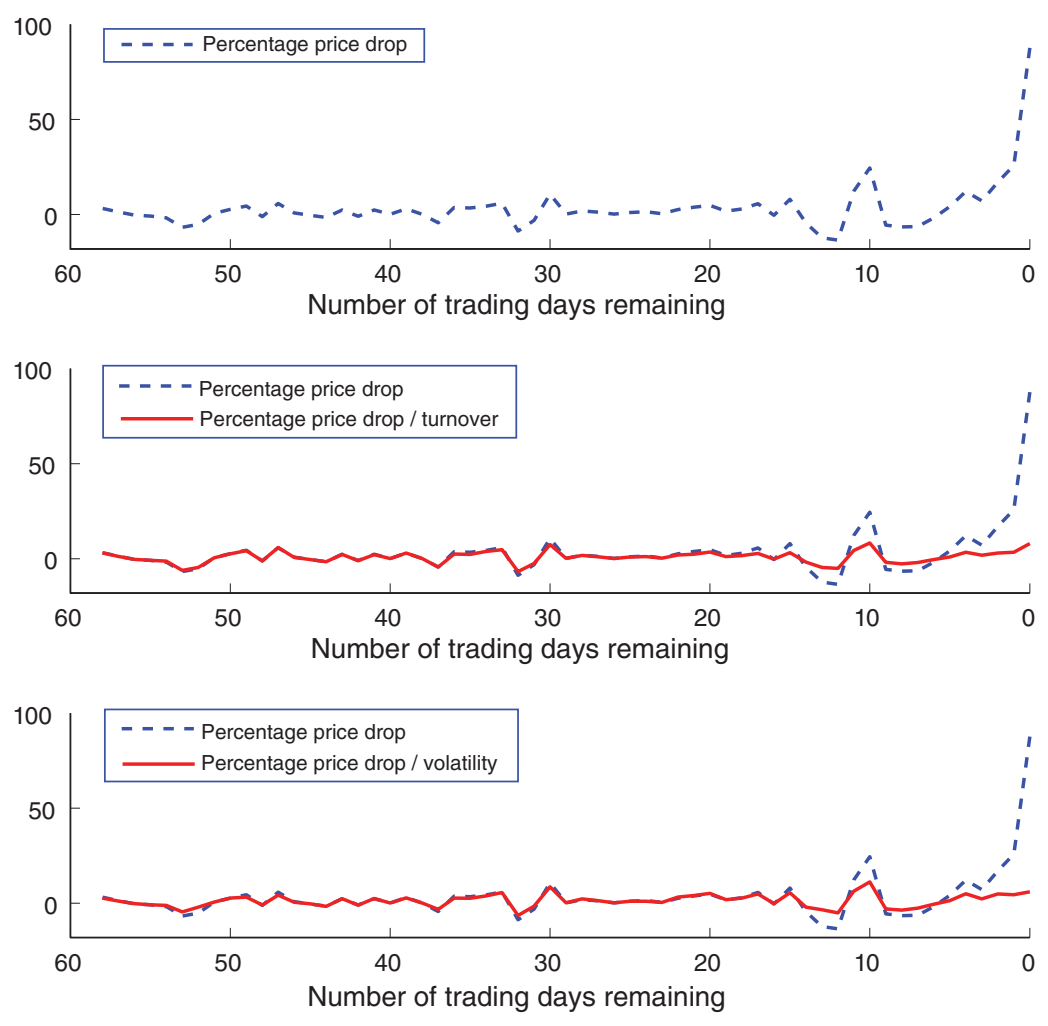

Figure 5. Average Warrant Price Drop

Notes: This figure shows the daily percentage drop of the average warrant price, along with its scaled versions (scaled by the average daily warrant turnover and the average 5-minute warrant return volatility (annualized), respectively), against the number of trading days remaining for the 17 put warrants in their respective zero-fundamental periods. The averaging is across all warrants with a given number of trading days remaining.

for the appearance of asset bubbles. In particular, Ackert et al. (2006) and Haruvy and Noussair (2006) find that relaxing short-sales constraints tends to lower prices. As we discussed before, the stringent short-sales constraints in the Chinese warrants market are also a key factor for understanding the warrants bubble.

Smith, Suchanek, and Williams (1988) interpret the bubble discovered in their experimental study as arising through agents' uncertainty about the behavior of others. More precisely, the bubble occurs because traders doubt the rationality of others and speculate that future prices may not track the fundamental value and instead would provide opportunities for trading gains.

As warrants are new to Chinese investors, it is reasonable for investors to doubt the rationality of others. There is evidence confirming the presence of naïve investors in this market. Table 3 shows that 13 warrants had irrational exercises by investors at losses, perhaps due to confusion between put and call warrants. The total loss averaged 243 thousand yuan per warrant.

The warrants bubble sample spans three years, during which those naïve investors could have learned through trading warrants and through observing warrants 
expiring out of the money. Then, it is reasonable to hypothesize that the warrants market should have become less speculative as naïve investors learned through their experience and uncertainty about others' rationality diminished. ${ }^{23}$

To examine this hypothesis, we split the 18 put warrants into two halves (each with nine warrants) based on their expiration dates and report separate statistics for the two subsamples in Tables 2 and 3 . Table 2 shows that the last nine warrants on average had a longer zero-fundamental period than the first nine. During the zero-fundamental periods, the last nine warrants had an average price level of 1.32 yuan, while the first nine had an average of only 0.53 yuan. The difference is significant with a $p$-value of 0.059 . Table 2 also shows that the last nine warrants had a greater number of trading days in violation of the fundamental upper bound than the first nine. The differences between these two subsamples in other dimensions, such as turnover, volatility, the magnitude of violating the fundamental upper bound, the last trading day dynamics, and irrational warrant exercises, are insignificant. Taken together, we do not see any evidence of investor learning. If anything, the last nine warrants had larger price bubbles over longer periods relative to the first nine.

In contrast, several experimental studies, e.g., Dufwenberg, Lindqvist, and Moore (2005); Haruvy, Lahav, and Noussair (2007); and Hussam, Porter, and Smith (2008), find that as traders gain more trading experience, the divergence in their price expectations is attenuated, and markets become thinner.

What explains the insignificant effect of investor learning in the warrants bubble during a prolonged period of three years? One possibility is that despite the presence of naïve investors in the warrants market, their impact was small. As a result, the learning of naïve investors was inconsequential. Another possibility is that the steady inflow of naïve investors to the warrants market was able to sustain the warrants bubble despite the learning of early arrived investors. According to a report by the CSRC (2008), the total number of individual brokerage accounts in China had increased from 80 million to 140 million from 2005 to 2007. It is conceivable that many of these new investors had been trading warrants. Consistent with this argument, a recent study by Binglin Gong, Deng Pan, and Dong-hui Shi (2010) analyzes all the accounts involved in trading one call warrant issued by the BaoGang Group and finds that the inflow of new investors had a positive impact on the warrant price. ${ }^{24}$ Due to the lack of account-level data, we will leave a more thorough analysis of the effect of naïve investors to future research. Since most experimental studies ignore the investor-inflow effect by focusing on a given set of subjects, the insignificant effect of investor learning documented by our analysis prompts more attention on the dynamics of inflow of new investors in future studies of prolonged asset bubbles.

\footnotetext{
${ }^{23}$ By analyzing a large sample of US individual investors, Amit Seru, Tyler Shumway, and Noah Stoffman (2010) find that a substantial part of learning by trading is reflected in their stopping of trading after realizing their poor ability.

${ }^{24}$ More specifically, the BaoGang call warrant was publicly traded between August 22, 2005 and August 23, 2006. During this period, it was slightly out of the money with Black-Scholes values mostly in the range of 10-50 pennies, although its traded prices were often above 1 yuan. Gong, Pan, and Shi (2010) obtain account-level data to construct a measure of new capital inflow to trading this warrant (i.e., purchases by accounts that had never held this warrant before) and show that this inflow variable is positively correlated with the warrant price.
} 


\section{G. The Feedback Loop Theory}

The behavioral finance literature suggests that various behavioral biases can lead individual investors to positively feedback to past returns. ${ }^{25}$ Motivated by these studies, Shiller (2000) advocates a feedback loop theory of bubbles. In this theory,

initial price increases caused by certain precipitating factors lead to more price increases as the effects of the initial price increases feedback into yet higher prices through increased investor demand. This second round of price increase feeds back again into a third round, and then into a fourth, and so on. Thus the initial impact of the precipitating factors is amplified into much larger price increases than the factors themselves would have suggested.

Does the feedback effect exist in the warrants market? We study the time-series dynamics of warrant return and turnover change in the bubble sample by running the following regressions:

$$
\begin{aligned}
\operatorname{RET}_{i, t}\left(\text { or } \triangle \text { TURNOVER }_{i, t}\right)= & h_{0}+h_{1} \cdot \operatorname{RET}_{i, t-1}+h_{2} \cdot \operatorname{RET}_{I, t-1}^{+} \\
& +h_{3} \cdot \Delta \text { TURNOVER }_{i, t-1} \\
& + \text { WARRANT FIXED EFFECT } \\
& + \text { MATURITY FIXED EFFECT }+e_{i, t},
\end{aligned}
$$

where $R E T^{+}=\max (0, R E T) . R E T_{i, t}$, and $\triangle T U R N O V E R_{i, t}$ refer to the one-period return and one-period proportional change in turnover of warrant $i$ in period $t$. We also include $R E T^{+}$, the truncated positive part of the lagged warrant return in our analysis, to examine asymmetry in the feedback effects. ${ }^{26}$ We examine the dynamics in different time intervals, including each period being five-minute, ten-minute, 30-minute, and one-hour intervals.

Table 6 reports the pooled regression results of warrant return on lagged warrant return and turnover change. Several interesting patterns emerge. First, the coefficient of lagged warrant return is significantly positive in regressions with five-minute and ten-minute intervals, but not with longer intervals such as 30 minutes and one hour. This result indicates a positive feedback effect in warrant returns, albeit only in frequencies much faster than what are typically observed in other markets. 27 For example, numerous empirical studies following Narasimhan Jegadeesh and

\footnotetext{
${ }^{25}$ Barberis, Andrei Shleifer, and Robert Vishny (1998) show that representativeness bias, a tendency to view events as typical or representative of some specific class, can lead a representative investor to extrapolate past price changes into expectations of future price changes. Kent Daniel, David Hirshleifer, and A. Subrahmanyam (1998) and Simon Gervais and Terrance Odean (2001) show that self-attribution bias, a tendency to attribute success to one's own ability but failure to external reasons, can also cause investors to feedback to past price increases. Hong and Stein (1999) provide a model to show that gradual diffusion of information among heterogeneous investors can lead to price momentum.

${ }^{26}$ We have also examined specifications without $R E T^{+}$. Dropping $R E T^{+}$does not affect the regression coefficients of other variables. We have also included the lagged change in volatility and found it does not change the effects of the return or the change in turnover.

${ }^{27}$ Market microstructure noise cannot explain the positive feedback effect in warrant returns, because it tends to generate negative autocorrelations in returns rather than positive ones, e.g., Richard Roll (1984).
} 
TABle 6-FeEdBack Dynamics

\begin{tabular}{|c|c|c|c|c|c|c|c|c|}
\hline \multirow[b]{2}{*}{ Sampling frequency } & \multicolumn{4}{|c|}{$R E T$} & \multicolumn{4}{|c|}{$\triangle T U R N O V E R$} \\
\hline & 5 minutes & 10 minutes & 30 minutes & 1 hour & 5 minutes & 10 minutes & 30 minutes & 1 hour \\
\hline Lag $R E T$ & $\begin{array}{c}0.137 \\
(2.42)\end{array}$ & $\begin{array}{c}0.193 \\
(2.94)\end{array}$ & $\begin{array}{c}-0.036 \\
(0.36)\end{array}$ & $\begin{array}{c}-0.090 \\
(0.68)\end{array}$ & $\begin{array}{c}1.148 \\
(3.48)\end{array}$ & $\begin{array}{c}1.157 \\
(4.59)\end{array}$ & $\begin{array}{c}0.947 \\
(2.84)\end{array}$ & $\begin{array}{c}1.298 \\
(3.98)\end{array}$ \\
\hline Lag RET+ & $\begin{array}{c}-0.103 \\
(1.28)\end{array}$ & $\begin{array}{c}-0.135 \\
(1.39)\end{array}$ & $\begin{array}{c}0.154 \\
(1.26)\end{array}$ & $\begin{array}{c}0.224 \\
(1.50)\end{array}$ & $\begin{array}{c}-1.390 \\
(2.13)\end{array}$ & $\begin{array}{c}-1.404 \\
(3.74)\end{array}$ & $\begin{array}{c}-1.039 \\
(3.57)\end{array}$ & $\begin{array}{c}-1.822 \\
(4.83)\end{array}$ \\
\hline Lag $\triangle T U R N O V E R$ & $\begin{array}{c}0.000 \\
(0.65)\end{array}$ & $\begin{array}{c}0.001 \\
(0.96)\end{array}$ & $\begin{array}{c}-0.001 \\
(0.72)\end{array}$ & $\begin{array}{c}0.002 \\
(0.45)\end{array}$ & $\begin{array}{c}-0.145 \\
(9.62)\end{array}$ & $\begin{array}{c}-0.146 \\
(9.72)\end{array}$ & $\begin{array}{l}-0.154 \\
(11.60)\end{array}$ & $\begin{array}{c}-0.124 \\
(8.30)\end{array}$ \\
\hline
\end{tabular}

Notes: This table shows the regression results of RET and $\triangle T U R N O V E R$ on lagged RET, RET + , and $\triangle T U R N O V E R$. $R E T$ is warrant return, $R E T+=\max (0, R E T), \triangle T U R N O V E R$ is the proportional change in warrant turnover. The regressions use the zero-fundamental sample (defined as Black-Scholes value less than 0.0005 , or for cash-settled NanHang if the settlement price will for sure exceed the strike). The regressions include warrant fixed effect and maturity fixed effect. The sampling frequency goes from 5 minutes to 1 hour. The $t$-statistics in parentheses are adjusted for heteroskedasticity and correlation within trading day.

Sheridan Titman (1993) find price momentum in individual stocks across the world in time intervals of around six months. The difference in the feedback frequencies between the warrants market and these stock markets is consistent with the dramatic difference in their turnover rates - the average daily turnover of the deep-out-of-themoney Chinese warrants is 328 percent (Table 2), while the average yearly turnover of US stocks is less than 100 percent. The fast feedback frequency of ten minutes in the warrants market confirms that this market operates at a much higher speed.

There is little evidence of asymmetric feedback of warrant returns to past warrant returns, because the coefficient of the truncated positive part of lagged warrant return is insignificant across all regression intervals. Furthermore, there is little evidence of intraday feedback effects in warrant returns to past turnover changes.

Table 6 also shows the pooled regression results of turnover change. Besides a significant mean-reverting effect in turnover, we also observe several other effects from this panel. First, consistent with the feedback effect in returns, there is a statistically significant positive feedback effect in turnover changes to past warrant returns in time intervals up to one hour (in unreported analysis, this positive feedback effect disappears in intervals of two hours and one day). Second, the response of turnover changes to past warrant returns is asymmetric. The coefficient of the truncated positive part of lagged warrant return is significantly negative in regressions with time intervals up to one hour, suggesting that drop in turnover in response to a negative warrant return is more pronounced than increase in turnover in response to a positive warrant return.

\section{H. Riding the Bubble}

Are there profit opportunities in the warrants market for smart investors to exploit? Given the presence of the positive feedback effect in the warrant returns, it is natural to evaluate momentum strategies. A common strategy involves buying past winners and simultaneously shorting past losers. We pool together the 17 put warrants in their zero-fundamental periods based on the number of trading days remaining. We construct hypothetical winner and loser portfolios based on the warrant returns in a formation period and then compute the portfolio returns in a holding period. Table 7 reports the portfolio returns under different portfolio specifications. We let the length 
Table 7-Momentum Profits

\begin{tabular}{lcccccc}
\hline \hline Return horizon & 5 minutes & 10 minutes & 30 minutes & 1 hour & 2 hours & 1 day \\
\hline Winner & -0.0005 & -0.0001 & -0.0013 & -0.0026 & -0.0033 & -0.0058 \\
& $(1.89)$ & $(0.14)$ & $(0.76)$ & $(0.96)$ & $(0.69)$ & $(0.68)$ \\
Loser & -0.0004 & -0.0015 & -0.0029 & -0.0058 & -0.0110 & -0.0179 \\
& $(1.35)$ & $(2.71)$ & $(2.33)$ & $(2.42)$ & $(2.69)$ & $(2.36)$ \\
\hline
\end{tabular}

Notes: This table shows the ex post returns of warrant portfolios sorted on lagged returns for warrants with the same number of trading days remaining during the zero-fundamental sample (defined as Black-Scholes value less than 0.0005 , or for cash-settled NanHang if the settlement price will for sure exceed the strike). Ex post returns are reported for winner and loser warrants (defined by lagged returns being above/below median). The return horizon ranges from 5 minutes to 1 day. The $t$-statistics in parentheses are adjusted for heteroskedasticity and correlation within trading day.

of the portfolio formation and holding periods be equal and vary it from five minutes to one day. The winner portfolio consists of the top half of warrants based on their returns in the formation period, while the loser portfolio consists of the bottom half.

We also examine the returns of the winner and loser portfolios separately. Interestingly, across all specifications, the returns of the winner portfolios are mostly negative and statistically insignificant. ${ }^{\sqrt{8}}$ In other words, it is not profitable for additional momentum traders to ride the warrants bubble. In contrast, the returns of the loser portfolios are negative across all specifications, and most of them are statistically significant. The existence of negative momentum profit again highlights the importance of short-sales constraints in driving the warrant price dynamics. If investors were able to short the loser portfolios, they would have been able to take advantage of the momentum strategies by shorting the losers and drive out the persistence of negative returns. The absence of positive momentum profit indirectly implies that smart investors might have been actively riding the warrants bubble and, by doing so, have eliminated additional opportunities for such momentum trades. This result is consistent with the theory of Abreu and Brunnermeier (2003) that rational arbitrageurs may choose to ride a bubble instead of attacking it, and with the evidence presented by Brunnermeier and Nagel (2004) that during the Internet bubble of the late 1990s many hedge funds (the likely rational arbitrageurs) had been active in riding the bubble. ${ }^{\text {Q }}$ Peter Temin and Hans-Joachim Voth (2004) also provide evidence of a well-informed investor riding the South Sea bubble.

\section{Conclusion}

This article examines a speculative bubble that occurred in 2005-2008 in China's warrants market. Despite being so deep out of the money that there was virtually no chance of getting back in the money before maturity, 17 put warrants had been traded

\footnotetext{
${ }^{28}$ Given the presence of the positive return feedback effect in five-minute and ten-minute intervals, why is riding past winners not profitable at these frequencies? This is due to the maturity effect in warrant prices. As discussed in Section IIC, there is a pronounced downward trend in prices, which largely offsets the short-run positive feedback. We have examined other definitions of winner and loser portfolios, such as top/bottom quartile, or positive/negative returns in the formation period. The results are similar and reported in the working paper version of this paper (NBER working paper \#15481).

${ }^{29}$ Some commentators had even suggested the presence of large manipulators using pump-and-dump strategies (e.g., Bradford Delong et al. 1990) to take advantage of naïve investors in the warrants market. Because of the lack of account level data, we cannot directly examine this hypothesis.
} 
more than three times a day at substantially inflated prices. Since the publicly observable underlying stock prices make the warrant fundamentals commonly known to all market participants and the warrants have predetermined finite maturities, this warrants bubble presents a unique opportunity to study a set of bubble theories. We find little evidence to support theories based on investors' hedging need, rational bubbles, agency problems of institutions, and investors' gambling behavior. Instead, our analysis highlights the joint effects of short-sales constraints and heterogeneous beliefs in explaining the price bubble across warrants and across time-to-maturity. We also confirm several key findings of the experimental bubble literature and point to the importance of inflow of new investors in understanding prolonged asset bubbles. Our study also finds direct evidence of positive feedback effects in warrant returns at short intervals of several minutes, and indirect evidence of smart investors riding the bubble.

\section{REFERENCES}

Abreu, Dilip, and Markus K. Brunnermeier. 2003. "Bubbles and Crashes.” Econometrica, 71(1): 173-204.

Ackert, Lucy F., Narat Charupat, Bryan K. Church, and Richard Deaves. 2006. "Margin, Short Selling, and Lotteries in Experimental Asset Markets.” Southern Economic Journal, 73(2): 419-36.

Ait-Sahalia, Yacine, Per A. Mykland, and Lan Zhang. 2005. "How Often to Sample a ContinuousTime Process in the Presence of Market Microstructure Noise." Review of Financial Studies, 18(2): 351-416.

Allen, Franklin, and Douglas Gale. 2000. "Bubbles and Crises.” Economic Journal, 110(460): $236-55$.

-Allen, Franklin, and Gary Gorton. 1993. "Churning Bubbles.” Review of Economic Studies, 60(4): 813-36.

Allen, Franklin, Stephen Morris, and Andrew Postlewaite. 1993. "Finite Bubbles with Short Sale Constraints and Asymmetric Information.” Journal of Economic Theory, 61(2): 206-29.

-Baker, Malcolm, and Jeffrey Wurgler. 2007. "Investor Sentiment in the Stock Market.” Journal of Economic Perspectives, 21(2): 129-51.

Barber, Brad M., Yi-Tsung Lee, Yu-Jane Liu, and Terrance Odean. 2009. "Just How Much Do Individual Investors Lose by Trading?" Review of Financial Studies, 22(2): 609-32.

Barberis, Nicholas, and Ming Huang. 2008. "Stocks as Lotteries: The Implications of Probability Weighting for Security Prices." American Economic Review, 98(5): 2066-2100.

- Barberis, Nicholas, Andrei Shleifer, and Robert Vishny. 1998. "A Model of Investor Sentiment." Journal of Financial Economics, 49(3): 307-43.

Blanchard, Olivier J., and Mark W. Watson. 1983. "Bubbles, Rational Expectations and Financial Markets.” National Bureau of Economic Research Working Paper 0945.

Brunnermeier, Markus K., Christian Gollier, and Jonathan A. Parker. 2007. "Optimal Beliefs, Asset Prices, and the Preference for Skewed Returns." American Economic Review, 97(2): 159-65.

Brunnermeier, Markus K., and Stefan Nagel. 2004. "Hedge Funds and the Technology Bubble." Journal of Finance, 59(5): 2013-40.

China Securities Regulatory Commission. 2008. China Capital Markets Development Report. Beijing: China Financial Publishing House.

Cochrane, John H. 2003. "Stocks as Money: Convenience Yield and the Tech-Stock Bubble." In Asset Price Bubbles: The Implications for Monetary, Regulatory, and International Policies, ed. W. C. Hunter, G. G. Kaufman and M. Pomerleano, 175-203. Cambridge, MA: MIT Press.

D'Agostino, Ralph, and Gary Tietjen. 1973. "Approaches to the Null Distribution of Square-Root b ${ }_{1}$." Biometrika, 60: 169-73.

Daniel, Kent, David Hirshleifer, and Avanidhar Subrahmanyam. 1998. "Investor Psychology and Security Market under- and Overreactions.” Journal of Finance, 53(6): 1839-85.

De Long, J. Bradford, Andrei Shleifer, Lawrence Summers, and Robert Waldmann. 1990. "Positive Feedback Investment Strategies and Destabilizing Rational Speculation.” Journal of Finance, 45(2): 379-95.

Dufwenberg, Martin, Tobias Lindqvist, and Evan Moore. 2005. "Bubbles and Experience: An Experiment." American Economic Review, 95(5): 1731-37.

Garber, Peter M. 2000. Famous First Bubbles: The Fundamentals of Early Manias. Cambridge, MA: MIT Press. 
-Gervais, Simon, and Terrance Odean. 2001. "Learning to Be Overconfident." Review of Financial Studies, 14(1): 1-27.

Gong, Binglin, Deng Pan, and Dong-hui Shi. 2010. "New Investers and Bubbles: An Analysis of the Baisteel Call Warrant Bubble." Unpublished.

Greene, William H. 1997. Econometric Analysis. Upper Saddle River, NJ: Prentice Hall.

- Harrison, J. Michael, and David M. Kreps. 1978. "Speculative Investor Behavior in a Stock Market with Heterogeneous Expectations." Quarterly Journal of Economics, 92(2): 323-36.

-Haruvy, Ernan, Yaron Lahav, and Charles N. Noussair. 2007. "Traders' Expectations in Asset Markets: Experimental Evidence.” American Economic Review, 97(5): 1901-20.

- Haruvy, Ernan, and Charles N. Noussair. 2006. "The Effect of Short Selling on Bubbles and Crashes in Experimental Spot Asset Markets." Journal of Finance, 61(3): 1119-57.

-Hauser, Shmuel, and Beni Lauterbach. 1997. "The Relative Performance of Five Alternative Warrant Pricing Models." Financial Analysts Journal, 53(1): 55-61.

-Hirota, Shinichi, and Shyam Sunder. 2007. "Price Bubbles Sans Dividend Anchors: Evidence from Laboratory Stock Markets." Journal of Economic Dynamics and Control, 31(6): 1875-1909.

-Hong, Harrison, Jose Scheinkman, and Wei Xiong. 2006. "Asset Float and Speculative Bubbles." Journal of Finance, 61(3): 1073-1117.

-Hong, Harrison, and Jeremy C. Stein. 1999. "A Unified Theory of Underreaction, Momentum Trading, and Overreaction in Asset Markets." Journal of Finance, 54(6): 2143-84.

-Hong, Harrison, and Jeremy C. Stein. 2007. "Disagreement and the Stock Market." Journal of Economic Perspectives, 21(2): 109-28.

-Hussam, Reshmaan N., David Porter, and Vernon L. Smith. 2008. "Thar She Blows: Can Bubbles Be Rekindled with Experienced Subjects?” American Economic Review, 98(3): 924-37.

- Jegadeesh, Narasimhan, and Sheridan Titman. 1993. "Returns to Buying Winners and Selling Losers: Implications for Stock Market Efficiency." Journal of Finance, 48(1): 65-91.

-Lamont, Owen A., and Richard H. Thaler. 2003. "Can the Market Add and Subtract? Mispricing in Tech Stock Carve-Outs." Journal of Political Economy, 111(2): 227-68.

- Lei, Vivian, Charles N. Noussair, and Charles R. Plott. 2001. "Nonspeculative Bubbles in Experimental Asset Markets: Lack of Common Knowledge of Rationality vs. Actual Irrationality." Econometrica, 69(4): 831-59.

Mei, Jianping, Jose A. Scheinkman, and Wei Xiong. 2009. "Speculative Trading and Stock Prices: Evidence from Chinese A-B Share Premia." Annals of Economics and Finance, 10(2): 225-55.

-Morris, Stephen. 1996. "Speculative Investor Behavior and Learning." Quarterly Journal of Economics, 111(4): 1111-33.

Ofek, Eli, and Matthew Richardson. 2003. "Dotcom Mania: The Rise and Fall of Internet Stock Prices." Journal of Finance, 58(3): 1113-37.

-Pastor, Lubos, and Pietro Veronesi. 2003. "Stock Valuation and Learning about Profitability." Journal of Finance, 58(5): 1749-89.

-Pastor, Lubos, and Pietro Veronesi. 2006. "Was There a NASDAQ Bubble in the Late 1990s?" Journal of Financial Economics, 81(1): 61-100.

-Porter, David P., and Vernon L. Smith. 1995. "Futures Contracting and Dividend Uncertainty in Experimental Asset Markets." Journal of Business, 68(4): 509-41.

-Roll, Richard. 1984. "A Simple Implicit Measure of the Effective Bid-Ask Spread in an Efficient Market." Journal of Finance, 39(4): 1127-39.

-Scheinkman, Jose A., and Wei Xiong. 2003. "Overconfidence and Speculative Bubbles." Journal of Political Economy, 111(6): 1183-1219.

-Seru, Amit, Tyler Shumway, and Noah Stoffman. 2010. "Learning by Trading." Review of Financial Studies, 23(2): 705-39.

Shiller, Robert J. 2000. Irrational Exuberance. Princeton, NJ: Princeton University Press.

-Smith, Vernon L., Gerry L. Suchanek, and Arlington W. Williams. 1988. "Bubbles, Crashes, and Endogenous Expectations in Experimental Spot Asset Markets." Econometrica, 56(5): 1119-51.

- Temin, Peter, and Hans-Joachim Voth. 2004. "Riding the South Sea Bubble." American Economic Review, 94(5): 1654-68.

Xiong, Wei, and Jialin Yu. 2009. "The Chinese Warrants Bubble." National Bureau of Economic Research Working Paper 15481.

Xiong, Wei, and Jialin Yu. 2011. "The Chinese Warrants Bubble: Dataset.” American Economic Review. http://www.aeaweb.org/articles.php?doi=10.1257/aer.101.6.2723. 